\title{
TITLE:
}

\section{ALEOCHARINAE (STAPHYLINIDAE, COLEOPTERA) FROM THE INTERTIDAL ZONE OF JAPAN}

\author{
$\operatorname{AUTHOR}(\mathrm{S})$ :
}

Sawada, Kohei

\section{CITATION:}

Sawada, Kohei. ALEOCHARINAE (STAPHYLINIDAE, COLEOPTERA) FROM THE INTERTIDAL ZONE OF JAPAN. PUBLICATIONS OF THE SETO MARINE BIOLOGICAL LABORATORY 1971, 19(2-3): 81-110

ISSUE DATE:

1971-10-30

URL:

http://hdl.handle.net/2433/175665

RIGHT: 


\title{
ALEOCHARINAE (STAPHYLINIDAE, COLEOPTERA) FROM THE INTERTIDAL ZONE OF JAPAN ${ }^{1)}$
}

\author{
KoHeI SAWADA \\ 15-10 Tennocho, Takatsuki, Osaka, Japan
}

With 10 Text-figures

To begin the taxonomic studies of Aleocharinae of the Japanese coasts with the halobious species, nine intertidal species mainly from the Southwest Japan have been investigated. They are highly specialized species living among or under stones between the high and low tide-marks on the seashore. In some species the eyes are small, the integument less chitinized and poorly pigmented. These may be the features adaptive to the life under the sea-water and appearing quite convergently, though their ecological meaning has not yet been cleared. Then, the nominative characters of the Aleocharinae are hazarded and concealed by such convergent appearances and consequently the taxonomic studies of those forms are made considerably difficult.

I wish to express my hearty thanks to Dr. T. TокіокA and to the staff of the Seto Marine Biological Laboratory for their constant help as well as to Prof. R. Yosin for the critical review of the manuscript. Also I am much indebted to Dr. Ian Moore of the University of California for the gift of valuable specimens.

\section{Bryothinusa CASEY, 1904}

Halesthenus K. SAWADA, 1955, syn. nov.

Typus: Bryothinusa catalinae CASEY, 1904

The genus Bryothinusa is quite different from Diaulota CASEY and its allies in the structure of the mouth-parts. The most prominent difference is the presence of a pair of distal setae on the prementum and the extraordinarily elongate shape of labial palpus, whose setae are aggregated on the external basal part of the palpus. $a$-sensilla of the labrum is characteristically broad and the anterior corner of the mentum is acutely produced. All these characters are, however, in common with the terrestrial genus Myllaena ERICHSON, 1837 and as the number of tarsal segment is 4,4,5 in both of them,

1) Contributions from the Seto Marine Biological Laboratory, No. 550.

Publ. Seto Mar. Biol. Lab., XIX (2/3), 81-110, $1971 . \quad$ (Article 8) 
it must be assumed that the genus Bryothinusa is a member of Myllaenini and not Phytosi, although in Myllaena the setae on the labial palpus are converted to be scaly.

The genus Halesthenus is most probably identical with Bryothinusa. I have not yet had any chance to investigate $B$. catalinae CASEY, the type species of Bryothinusa, but examined Bryothinusa sp. from Hong Kong, determined and kindly presented to me by Dr. I. Moore, who has already studied the cited species in detail.

\section{Bryothinusa minuta (K. SAwADA, 1955)}

(Text-fig. 1)

\section{Halesthenus minutus K. SAwada, 1955}

Male: Pale reddish brown in ground colour and subopaque. Uniformly pale on the anterior half and darker to the posterior end of the abdomen; antennae and legs are paler. Head is orbicular in outline, evenly rounded laterally, gently convex above and deplanate on the middle; the integument bears very short, dense pubescence and fine reticulation all over. Eyes are very small, placed just behind the antennal insertion; each consists of some 4 coarse facets with long pubescence. Antenna is mostly filiform, not dilated distally and in relative length as: I $13 \times 6:$ II $10 \times 6.5$ : III $5.5 \times 6.2$ : IV $6.0 \times 6.0: \mathrm{X} 9 \times 7.5: \mathrm{XI} 17.5 \times 7.6$. Labrum (fig. B) is as long as wide, subtruncate and with a fine incision on each side of the apex; seta $p-1, p$-2 are subequally short; $m-2$ is fairly longer than $m-1 ; d-1, d-2$ are normally long and curved; the proximal row is short and placed close to $d-2$; the medial row is also short, located on the level of $d-1$; the distal row is nearly longitudinal; there are up to $2+2$ long secondary setae. The $a$-sensilla of labral margin (fig. C) is normally long, but strikingly spatulate and fusiform, whereas $b$ is reduced to a fine usual seta; $c$ similarly small and slender. Mandible (fig. D) is elongate, curved to an obtuse apex and with some 4 short setae laterally; the right mandible bears an inner tooth at about the middle. The prostheca is narrow, produced proximally and its marginal cilia tend to be coarser basally. Maxillary palpus (fig. E) is 4-segmented; segment I is as long as wide; II is narrow, sinuate and coarsely reticulate on the inner face; III is longer and broader than II, widest at the anterior one-third and densely pubescent; IV is very short, with large blunt apical sensilla ( $\mathrm{s}$ in fig. E) it would correspond to the apical spinula of other Aleocharinae. Lacinia (fig. E) is well sclerotized, narrowly elongate, straight and lightly curved on apex; the distal comb occupies the anterior half of the inner margin and composed of 5 short, blunt processes, each of which has a fine median spinule; proximally there is a row of spines whose arrangement and form are apparently specific. In the present species there are five spines, the penultimate two are situated near together and the most proximal one is always straight; parallel to these spines there is a row of some 4 small setae, a feature peculiar to the genus Bryothinusa. Galea (fig. F) is styliform, narrowed distally and with some sensory pores; the distal lobe is almost 


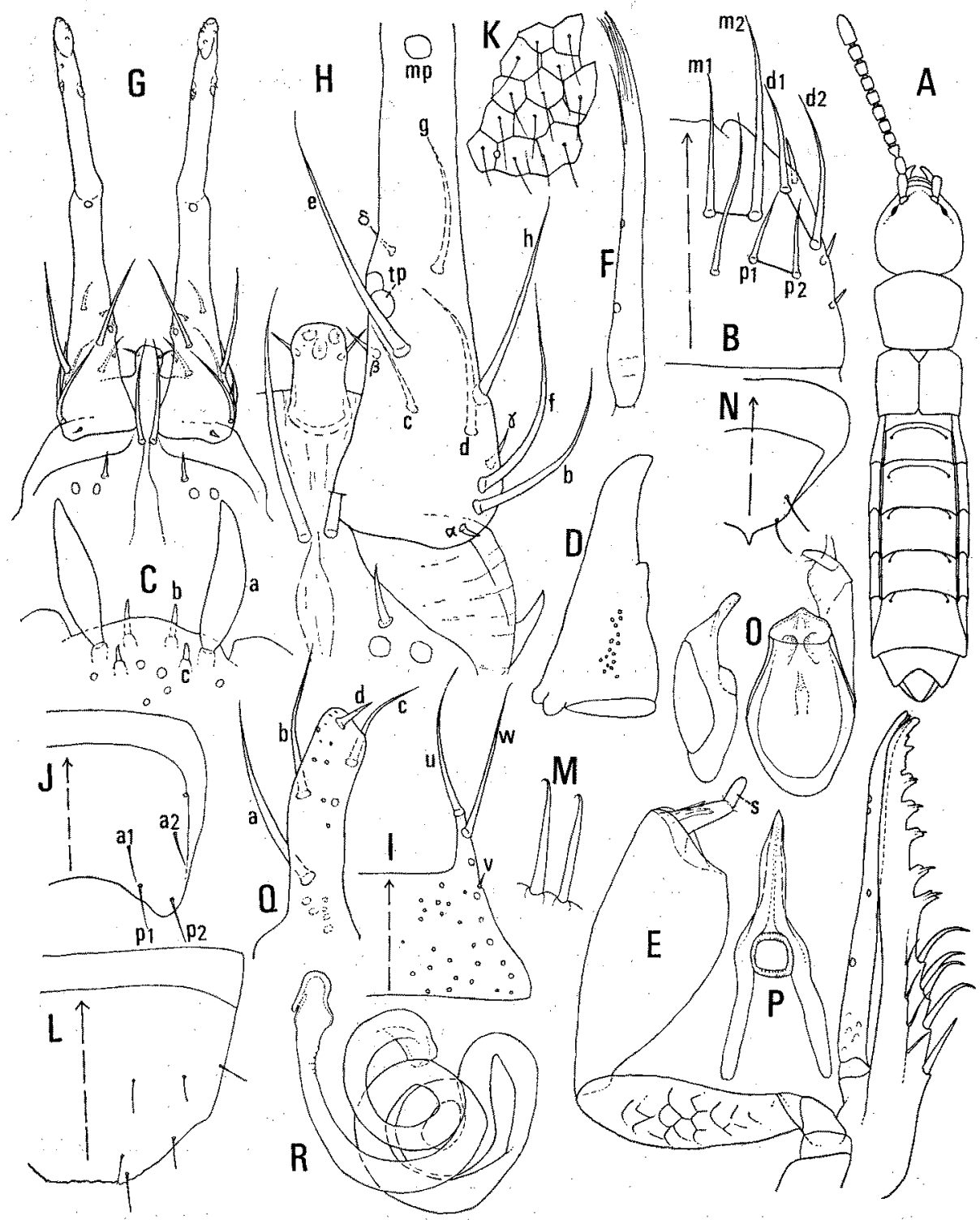

Fig. 1. Bryothinusa minuta (K. SAWADA) from the Tokara Is. A, Habitus; B, Labrum; C, Labral margin; D, Right mandible; E, Maxillary palpus, lacinia \& galea; F, Galea; G, H, Labium; I. Mentum; J. Terg. VIII; K, Microsculpture of terg. VIII; L, Stern. VIII; M, Marginal setae of stern. VIII; N, Terg. IX; O, Aedeagus (dors. \& lat. view); $P$, Copulatory piece; $Q$, Distal sclerite of left paramere; $R$, Spermatheca. 
styliform and ending to fine branches. Labial palpus (figs. $\mathrm{G}, \mathrm{H}$ ) is enormously long and seemingly 2-segmented; the setae are aggregated near the outer proximal corner of the basal segment; $\alpha$ is small; $\beta$ is separated from $t p ; \gamma$ is short, subequal to $\beta$ in length and placed anterior to $f ; \delta$ is close to the longitudinally arranged $t p ; b$ is close to $\alpha$; $d$ is longer than $c ; e$ is absent; $f$ is subequal to $b$ in length and just distal to $b ; g$ is far remote from $m p$ and slightly posterior to $\delta$. Glossa (fig. $\mathrm{H}$ ) is short, broad and blunt; there is a pair of small spines and some sensillate structure; the paired basal pores of glossa are characteristically absent. Paraglossa is completely reduced. The distal setae of prementum are distinct; the median area is membraneous and devoid of pseudopores; one setal and 2 real pores are well-developed on the lateral area. Mentum (fig. I) is broadly and straightly truncate in front and distinctly produced at the external corner to a slender process; seta $u$ is inwardly curved and placed on the apex; $w$ is placed just behind $u$ and subequal to it in length; $v$ is small, remote from $w$ and mingled with secondary setae. Pronotum is weakly convex above, narrowed behind and with straight lateral margin; the integument has very fine, short pubescence and indistinct microsculpture throughout; the lateral erecting setae are 3 in number, but inconspicuous. Prothoracic epipleura are entirely visible from side. Prosterum is briefly pointed and without median carina. Procoxal cavity is broadly opened behind. Elytron is not emarginate behind, similarly pubescent and sculptured as pronotum. Metathoracic wing is absent. Tarsal number as 4,4,5, their ratio as 8:9:10:12.5 in fore-; 10:8:7.5:13 in mid-; 15:9:9.5:8:15 in hind-legs. No empodium on each tarsus. Abdomen is fincly punctured and pubescent. Tergite VIII (fig. J) has the posterior margin deeply emarginate in full length; among 4 short principal setae $a-1$ is slightly shorter than $p-1 ; a-2$ is remote from the fairly reduced stigma; the microsculpture on the middle area is indistinctly reticulate, bearing a fine seta on each reticulum. Terg. IX is modified as in fig. $\mathrm{N}$, but the median posterior process is variable in form. Sternite VIII (fig. L) is truncate behind, angulate laterally and bearing short principal setae. Tarsal number as 4,4,5, their ratio as $8: 9: 10: 12.5$ in fore-; 10:8:7.5:13 in mid-; 15:9:9.5:8:15 in hind-legs. No empodium on each tarsus.

Aedeagus (fig. $\mathrm{O}$ ) is $0.23 \mathrm{~mm}$ long. In dorsal view the median lobe is oblong-ovate in outline and dilated in the middle. Copulatory piece (fig. P) has a long, pointed apical process and a pair of narrow, diverging posterior processes; the annellus is large and situated at the middle of the corpus. Paramere has elongate distal sclerite (fig. Q) bearing 4 setae; $a$ is the longest; $b$ is smaller and at the middle of the sclerite; $d$ is apically situated, small and much shorter than $c$.

Length $1.60 \mathrm{~mm}$ (head long $0.26 \mathrm{~mm} \times$ wide $0.28 \mathrm{~mm}$ : pronotum $0.24 \mathrm{~mm} \times$ $0.28 \mathrm{~mm}$; elytra $0.22 \mathrm{~mm} \times 0.28 \mathrm{~mm}$ ).

Female: Terg. VIII and IX is alike those of the male, but stern. VIII is not very produced; its posterior margin is broadly truncate, feebly sinuate in the middle and fringed with ca. $8+8$ minutely hooked spines (fig. M). Spermatheca (fig. R) has a long duct coiled many times; the bursa is small, lightly constricted and dilated, the wall 
just before the bursa is finely wrinkled.

Specimens examined: $4 \hat{\delta}, 2$ 우 Nakanoshima in the Tokara Is., Pref. Kagoshima, holo-, allo- and paratypes, (4. VI. 1953, S. UENo); 1 占 Seto, (14. IV. 1970, K. SAwA. DA); 1 占 Shionomisaki, (16. V. 1970, K. SAwADA); 1 令 Kirimezaki, (15. V. 1970, R. Yosii); ditto, 2 우, (15. IV. 1970, K. SAwadA); 1 우, Tomogashima off Kada, (28. V. 1970, K. Sawada), all in Pref. Wakayama; head only, Kotsubo, (31. X.1954, T. Aokr), $2 \hat{o}$ Koyurugi, (12. V. 1953, T. AokI), all in Pref. Kanagawa; $1 \hat{\delta}$, IzuOshima, Pref. Tokyo, (6. V. 1955, T. Aokı).

The species is unique by its small body size, pale colouration and reduced eyes. Spatulate $a$-sensilla of the labral margin and distally removed $\gamma$ setula of the labial palpus are also characteristic.

\section{Bryothinusa tsutsuii (K. SAWAdA, 1955)}

\section{(Text-fig. 2)}

Halesthenus tsutsuii K. SAWADA, 1955; H. serpentis K. SAWADA, 1955

Male: Ground colour is dusky yellow, subopaque and sericeous. Head is a little darker than pronotum; abdomen is infuscate at the middle; antennae and legs are uniformly pigmented. Head is evenly rounded laterally, weakly convex, but broadly deplanate above and minutely sculptured all over. Eyes are small and composed of some 8 coarse facets bearing long pubescence. Antenna is filiform; ratio of segments as: I $24 \times 9.5$ : II $20 \times 10$ : III $12 \times 9$ : IV $14 \times 9.3: \mathrm{X} 14 \times 12: \mathrm{XI} 23 \times 12.3$. Labrum (fig. B) is alike $B$. minuta, but apparently shorter; seta $p-1$ is shorter than $p-2 ; d-1$, $d-2$ are equally long; one secondary seta is long, subequal to $m-1$ in length. The $a$-sensilla (fig. C) is spatulate, but not so distinct as in $B$. minuta; $b, c$ are similarly elongate and pointed on apex. The right mandible (fig. D) has a median denticle and some minute pores proximally. Maxillary palpus is more slender than in $B$. minuta. Lacinia and galea are also as in B. minuta, but the distal comb of $B$. tsutsuii is more slender and furnished with a row of 6 setac parallel to the inner margin. Setula $\alpha$ of the labial palpus (fig. $\mathrm{E}$ ) is on the basal margin of the segment; $\beta$ is remote from $t p ; \gamma$ is postero-external to seta $f ; a$ is anterior to $\beta ; b$ is much shorter than and posterior to $f ; g$ is slightly anterior to $\delta$ in position. Glossa (fig. $\mathrm{E}$ ) is very short, rounded and with 2 setae laterally. Prementum (fig. E) is broadly rounded laterally and without pseudopores; 2 real and 1 setal pores of the lateral area are placed close to each other. Mentum (fig. F) is as in B. minuta, but the prolonged external corner is shorter; seta $u, w$ are similarly arranged, whereas $v$ is placed more posteriorly. Pronotum is similarly punctured and sculptured as the head, gently convex above, but the broadly deplanate median area is depressed behind; the lateral margin is weakly rounded in full length and with 3 erecting setae. Elytron is obsoletely emarginate behind. Metathoracic wing is absent. The tarsal number is $4,4,5$, their relative lengths as $8: 7.5: 7: 11$ 


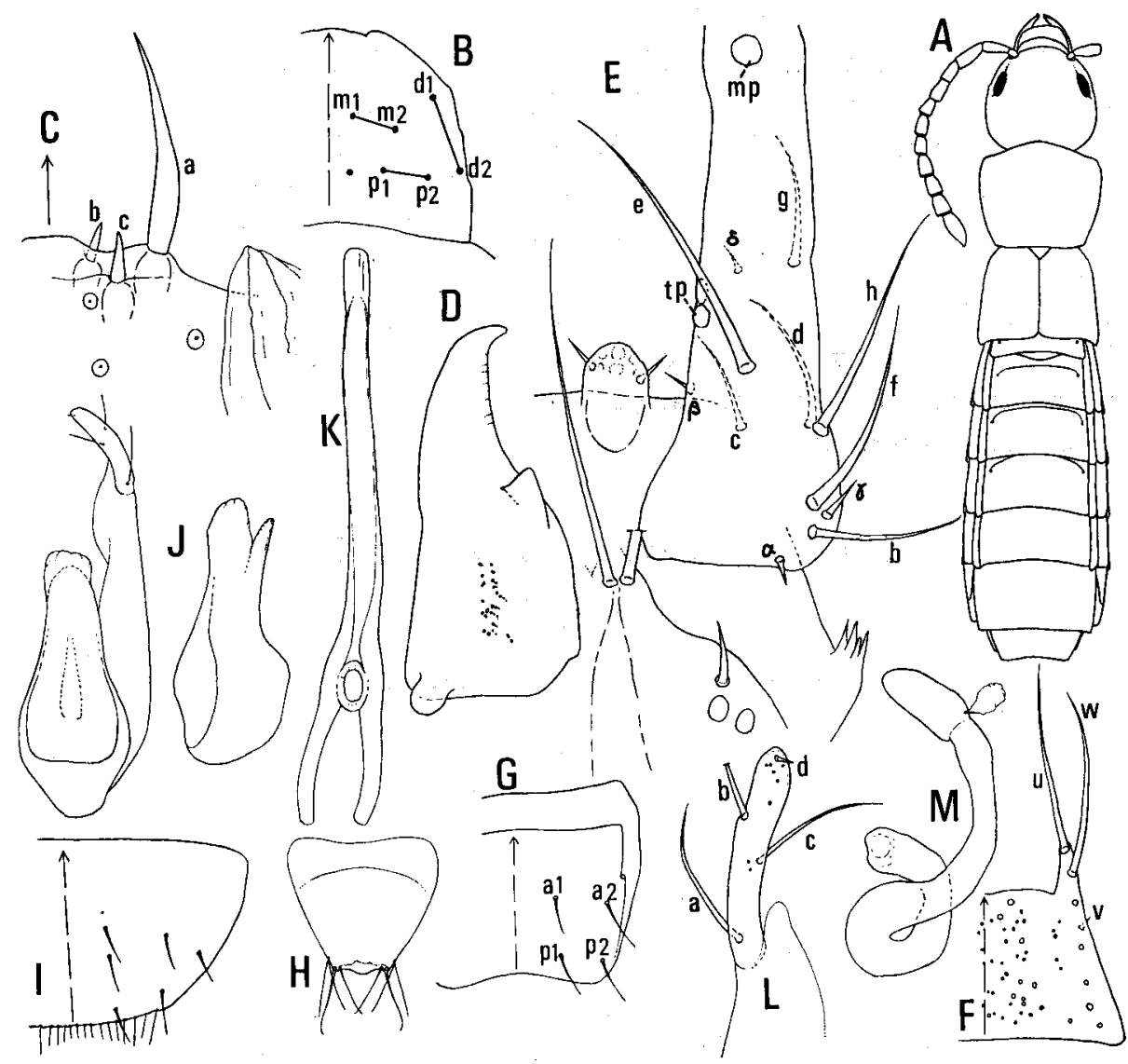

Fig. 2. Bryothinusa tsutsuii (K. SAwADA) from the Tokara Is. A, Habitus; B, Labral chaetotaxy; C, Labral margin; D, Right mandible; E, Labium; F, Mentum; G, Terg. VIII; H, Terg. IX of female; I, Stern. VIII; J, Aedeagus (dors. \& lat. view); K, Copulatory piece; L, Distal sclerite of left paramere; M, Spermatheca.

in fore-; 10:8:7.5:12.5 in mid-; 14:8:7.5:7.5:14 in hind-legs. Empodium of all tarsi is as long as the claw. Abdomen is almost parallel, but a little dilated behind and densely pubescent throughout. Tergite VIII (fig. G) is shallowly emarginate behind; among 4 principal setae, $a-1, p-1$ are shorter than others; $a-2$ is nearer to the stigma than to $p-2$; the microsculpture on the middle forms a pentagonal reticulation, each mesh with one seta. Terg. IX (fig. H) is acuminate toward the extremity, where it is quite membraneous, somewhat rounded in the middle and furnished with some long setae laterally.

Aedeagus (fig. $\mathrm{J}$ ) is $0.38 \mathrm{~mm}$ long. In dorsal view the median lobe is lightly narrowed distally and with the broadly obtuse apical lobe. Copulatory piece (fig. K) is enormously long, parallel and with a very thin, transparent apical plate; the basal 
portion of it is composed of a pair of short, diverging sclerites to which a small annellus is attached. Paramere (fig. $J$ ) is long, far extending the apex of the median lobe; the distal sclerite (fig. L) is narrowly elongate; seta $a, b$ are far apart from each other; $c$ is long and placed in the middle of the inner margin, while $d$ is strongly reduced.

Length $2.6 \mathrm{~mm}$ (head long $0.46 \mathrm{~mm} \times$ wide $0.44 \mathrm{~mm}$; pronotum $0.40 \mathrm{~mm} \times 0.46$ $\mathrm{mm}$; elytra $0.39 \mathrm{~mm} \times 0.48 \mathrm{~mm}$ ).

Female: Terg. VIII is as in the male, but sternite VIII (fig. I) is short, broadly subtrucate behind and with 6 short principal setae in addition to simple, fine setules fringing the hind margin. The duct of spermatheca (fig. $M$ ) is long and coiled up; the bursa is unusually narrow, oblong and without the umbilicus.

Specimens examined: $1 \hat{\delta}, 1$ 우, Takarajima in the Tokara Is., holo-and allotype, (29. V. 1953, S. Mryaмoтo), 3 ㅇ, Nakanoshima in the Tokara Is. (9. VI. 1953 S. Ueno), all in Pref. Kagoshima.

As compared with $B$. minuta, the body is larger, a-sensilla of the labral margin is more slender, $\gamma$ setula of the labial palpus is more proximal, glossa is shorter and copulatory piece is longer in this species. Spermatheca of the female is simple. $H$. serpentis $\mathrm{K}$. SAwADA, 1955 coincides well with $H$. tsutsuii in all characteristics. The difference in the labial palpus between the two mentioned in my previous paper is attributable to an artifact caused by shrinking of the sample.

\section{Bryothinusa nakanei (K. SAWADA, 1955)}

(Text-fig. 3)

Halesthenus nakanei K. SAWADA, 1955

Male: Intensively brown in ground colour and subopaque; head, pronotum and femora of all legs are similarly coloured, elytra are paler toward the extremity; abdomen is almost black; antennae are uniformly brownish leaving a little infuscate basal segments. Head is completely and strongly rounded laterally and gently convex above; the frontal margin is faintly emarginate in the middle, with long setae; the integument is covered with short pubescence, which are denser toward the occiput. Eyes are characteristically large, with coarse facets and long pubescence. Ratio of antennal segments as I $24 \times 7.5:$ II $18 \times 8:$ III $7 \times 7:$ IV $8 \times 7.2: \mathrm{X} 8 \times 9.5: \mathrm{XI}$ $18 \times 10$, Labrum (fig. B) is dilated basally and acuminate toward the apex, which is furnished with an apical incision that is much more conspicucus than in B. minuta, remarkably the apical-most sensilla of the 3 lateral sensillae is developed to a large truncate element ( $s$ in fig. B); seta $p-1, p-2$ are subequally short and curved upwards; $d-1$ is long, surpassing $m-1$ in length and on the level with $m-2$; the proximal row is twice as long as the medial row; one long secondary seta is present. The $a$-sensilla of the labral margin is long (fig. C), setiform and medially dilated; $b$ is short and pointed; $c$ is much shorter than $b$. Mandible is as in the preceding species but narrower. The 


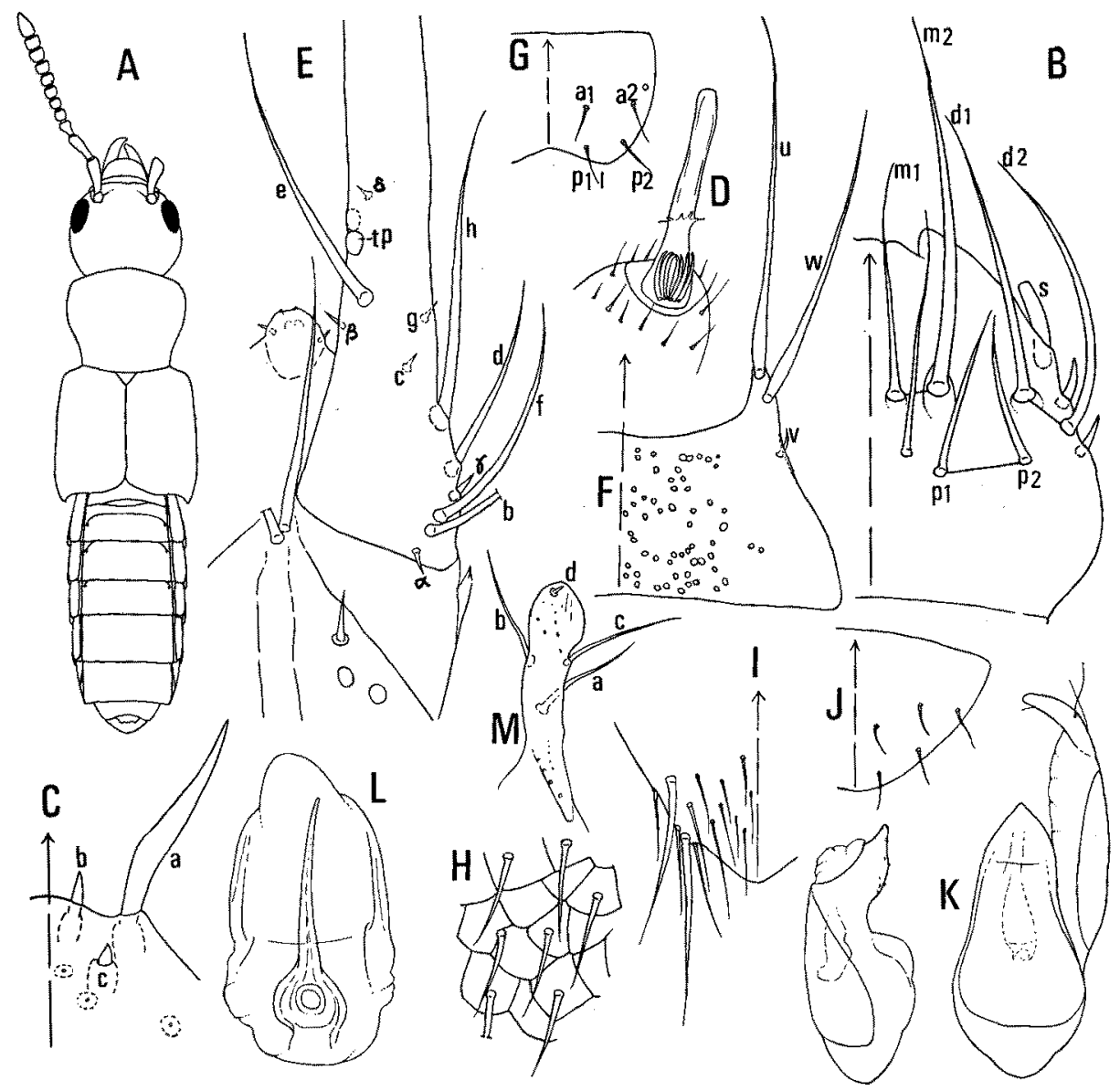

Fig. 3. Bryothinusa nakanei (K. SAWADA) from the Tokara Is. A, Habitus; B, Labrum; C, Labral margin; D, Segment IV of maxillary palpus; E, Labium; F, Mentum; G, Terg. VIII; H, Microsculpture of terg. VIII; I, Terg. IX; J. Stern. VIII; K, Aedeagus (dors. \& lat. view); L, Copulatory piece; M, Distal sclerite of left paramere.

prostheca is fringed only on its anterior half. Maxillary palpus is narrowly elongate; segment I has a long seta and a minute setula together with more than 2 sensory pores apically; II is quite slender, longer than III and with very fine, short pubescence and elongate reticulation throughout; III is slender, similarly pubescent and weakly dilated at the middle as in II ; IV is strongly reduced and with curved filamentous sensillae reaching the middle of the segment, the apical appendix is much longer than the segment itself, the two parts are delimitate by the thin, radiating leaflet as in fig. D. Lacinia is very slender and long; the distal comb consists of 7 spinulating processes, but 2 apical ones are smaller; 4 curved spines behind the distal comb are dilated in the middle. Galea is quite spiniform, weakly dilated before the apex, where it is finely furcate; instead of the imbricate reticulation in other species some minute spinulae 
are present. Labial palpus (fig. E) is very long; in the chaetotaxy setula $\alpha$ is on the basal margin of the segment; $\beta$ is posterior to $a ; \gamma$ is just distal to $f ; \delta$ is placed near $t p$, which are arranged in a longitudinal order; seta $a$ is on the level of $g$, which is strongly reduced to minute setula; $c$ is also minute and far distal to $h$ in position; $d$ is normally long, situated close to $\gamma ; e$ is missing. Glossa (fig. E) is strongly reduced and almost semicircular in outline; the spine on each side is very short. Prementum (fig. E) is acuminate in front, with long distal setae arranged longitudinally, a unique character of this species. Mentum (fig. F) has the shortly produced lateral corner and seta $u$, $w$ tend to be dilated near their basis; there are numerous secondary setae and pores, the formers are well-developed on the lateral margin. Pronotum is somewhat convex above, declivous antero-externally and weakly depressed on the middle near the base; 3 lateral erecting setae are short; the surface is similarly pubescent and sculptured as the head. Prosternum is quite obtusely convex on the middle. Elytron is fairly emarginate behind, the external corner is quite obtusely produced behind; the surface is finely and densely pubescent. Metathoracic wing is present. Fore- and mid-legs have densely pubescent tibiae. Tarsal number is $4,4,5$, their ratio as $7: 6: 5: 9.5$ in fore-; 10:7:6:10 in mid-; 12:7:7:6:12 in hind-legs. Empodium of each tarsus is curved, as long as the claw. Abdomen is more sparsely pubescent and more roughly sculptured than the elytra. Tergite VIII (fig. G) is distinctly emarginate behind and broadly rounded laterally; among 4 principal setae $a-2$ is nearer to the stigma than to $p-2$; microsculpture on the middle area is composed of the setigerous reticulation, a little rougher than in B. tsutsuii. Sternite VIII (fig. J) is acuminate, narrowly rounded apically and with $5+5$ short setae. Tergite IX (fig. I) is strongly acuminate to the pointed apex and clothed with coarse setae and fine pubescence excepting the produced apical part.

Aedeagus (fig. $\mathrm{K}$ ) is $0.26 \mathrm{~mm}$. In dorsal view the median lobe is gradually narrowed to the triangular apical lobe. Copulatory piece (fig. L) is extremely small, $0.054 \mathrm{~mm}$ in length and embedded in the oblong suspensoria; the apical process is styliform and with the small, rounded corpus with an annellus. The distal sclerite of paramere (fig. $\mathrm{M}$ ) is narrowly elongate and lightly spatulate apically; seta $a, b, c$ are equally long, while $d$ is almost completely reduced and hyaline.

Length $2.1 \mathrm{~mm}$ (head long $0.36 \mathrm{~mm} \times$ wide $0.44 \mathrm{~mm}$; pronotum $0.40 \mathrm{~mm} \times$ $0.47 \mathrm{~mm}$; elytra $0.52 \mathrm{~mm} \times 0.54 \mathrm{~mm}$ ).

Specimens examined: $1 \hat{\circ}$ Takarajima in the Tokara Is., Pref. Kagoshima, (holotype, 29. V. 1953, S. Ueno); $1 \hat{\circ}$, Aburatsubo, Pref. Kanagawa, (26. VI. 1955, T. АокI).

The species is easily distinguished from others. It is more deeply pigmented and with larger eyes. The lateral sensilla of the labrum is strikingly large, maxillary palpus is apically enlarged and seta $c, g$ of the labial palpus are strongly reduced. In the male genital organ the copulatory piece is styliform. In one male example from Aburatsubo, the sensilla of the labrum is pointed and $h$ of the labial palpus is more distal in position, but it is concordant with the Tokara sample in all other respects. 


\section{Bryothinusa algarum sp. n.}

(Text-fig. 4)

Male: Reddish yellow in ground colour and with sericeous lustre; the fore-part is uniformly pigmented, but abdomen is darker posteriorly; antennae and legs are a little paler. Head is quite oval, more or less produced anteriorly, gently convex above, but broadly deplanate on the middle of the epicranium; the integument has extremely sensitive pubescence and sculpture; the frontal margin is a little emarginate in the middle. Eyes are small, not produced from the surface and composed of about 8 coarse facets together with long pubescence. Antenna is filiform, not dilated distally and with ratio of segments as I $23 \times 11:$ II $20 \times 9:$ III $11 \times 7.5:$ IV $12 \times 8: \mathrm{X}$ $13 \times 11: \mathrm{XI} 23 \times 10$. Labral seta $p-1, p-2$ (fig. B) are subequally short and curved upwards; $d-1, d-2$ are equal in length; the medial row is not shorter than the distal row; only one long secondary seta is present. The $a$-sensilla of the labral margin (fig. C) is broad at the middle and then abruptly tapering to an acute apex, while $b, c$ are equally narrow and setiform. Mandible is elongate, lightly curved on the apex and with dense pores near the base; the right mandible has a basal tooth. The prostheca is broad and with a narrow sclerotized part at the middle. Segment I of the maxillary palpus is longer than wide, with a few pores apically; II is relatively narrow, nearly straight and covered with the coarse, distinct reticulation throughout; III is more dilated than II and retracted toward the apex; IV is very short and obtusely produced apically, where it is neither verrucose nor spinulose; the flamentous basal sensillae are quite thin and hyaline. Lacinia is alike that of $B$. tsutsuii, but the apical hook is more robust and obtuse; each process of the distal comb is seemingly shorter. Galea is styliform, ciliate apically. Setula $\beta$ of the labial palpus (fig. D) is minute, situated at the level of seta $h ; \gamma$ is placed anterior to $f$, but considerably remote from $h ; \delta$ may be posterior to $g$ in position, but $b$ is just behind $f$. Glossa (fig. D) is short, relatively narrow and bisetose. Prementum (fig. D) is triangular in shape; 1 setal and 2 real pores are as in B.tsutsuii. Mentum (fig. E) is distinctly acuminate anteriorly and lightly emarginate at the middle of the anterior margin; the produced external corner is rather short; seta $u, w$ are situated close together near the apex; $v$ is small and placed at the level of the anterior margin. Pronotum is gently convex above, feebly rounded and weakly retracted laterally; a faint sinuation is observed just before the posterior corner; the integument is alike that of the head. Elytron has the slightly produced external corner and the pubescence are finer and denser than on the pronotum. Metathoracic wing is absent. The tarsal segments are $4,4,5$, their relative lengths as $6: 6: 6: 10$ in fore-; 8:7:7:11 in mid-; 12:7:7:6:13 in hind-legs. Each empodium is longer than the claw and not acicular but spatulate apically. Abdomen is densely pubescent throughout. The tergites and sternites are similar to those of $B$. tsutsuii, but the former is more deeply emarginate, while the latter is acuminately produced behind. 


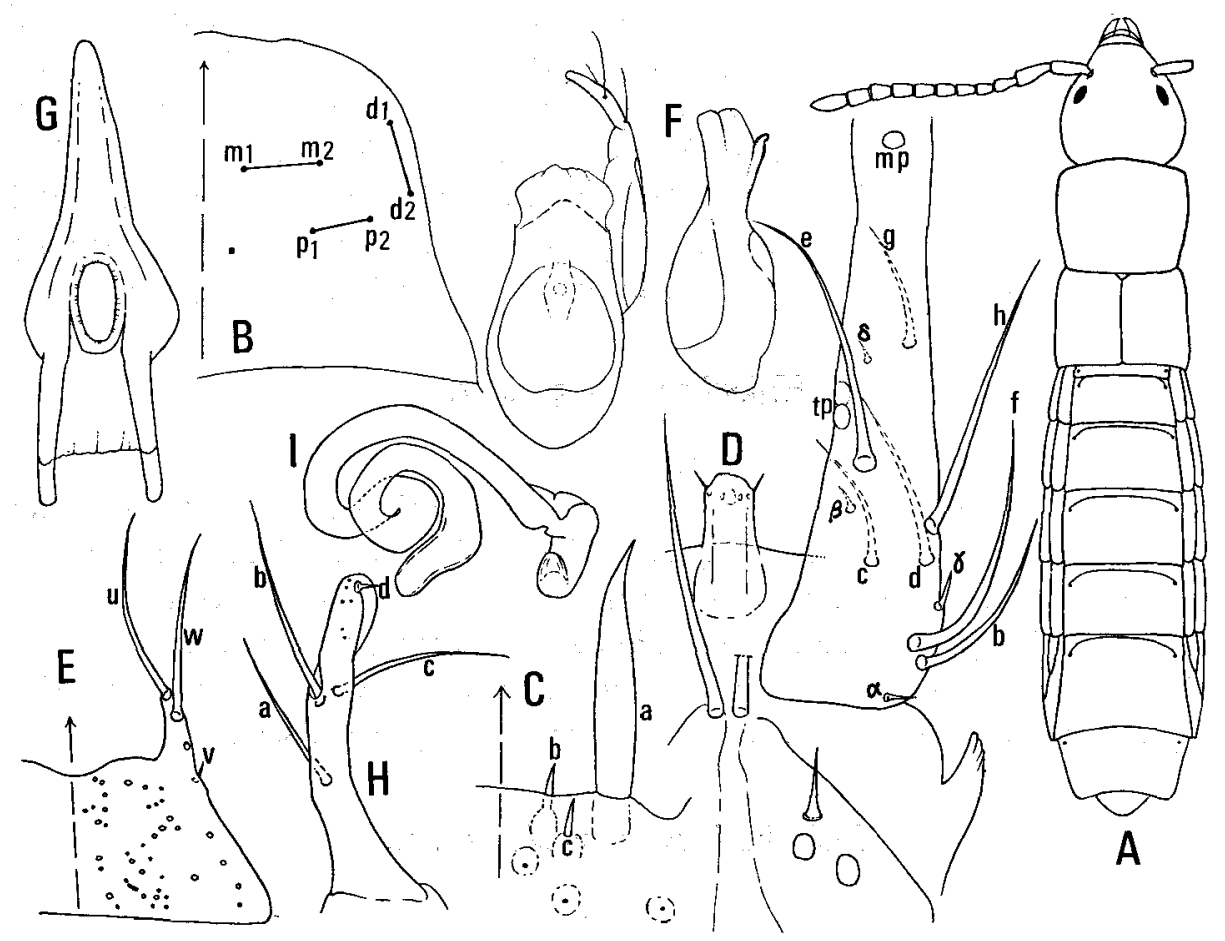

Fig. 4. Bryothinusa algarum sp. n. A, Habitus; B, Labral chaetotaxy; C, Labral margin; D, Labium; E, Mentum; F, Aedeagus (dors. \& lat. view); G, Copulatory piece; H, Distal sclerite of left paramere; I, Spermatheca.

Aedeagus (fig. F) is $0.33 \mathrm{~mm}$. In dorsal view the median lobe is broadly dilated and weakly constricted before the apex; the apical lobe is triangularly pointed and lightly bent. Copulatory piece (fig. G) is $0.095 \mathrm{~mm}$; the apical process is gradually tapering to the obtuse, hyaline apex; the basal part is laterally dilated and a pair of basal processes are elongate and embracing the large, oblong annellus. The distal sclerite of the paramere (fig. $\mathrm{H}$ ) is narrowly long and twisted apically; seta $a$ is at about the basal one-third; $b . c$ are placed close together; $d$ is reduced.

Length $2.50 \mathrm{~mm}$ (head long $0.40 \mathrm{~mm} \times$ wide $0.46 \mathrm{~mm}$; pronotum $0.40 \mathrm{~mm} \times$ $0.46 \mathrm{~mm}$; elytra $0.36 \mathrm{~mm} \times 0.46 \mathrm{~mm})$.

Female: Terg. VIII is more shallowly emarginate than in the male. Sternite VIII is alike that of $B$. tsutsuii. Spermatheca is complicated as shown in fig. I; the anterior part of the duct is large and well sclerotized; the bursa is clearly constricted basally, bent upwards apically and devoid of the umbilicus.

Holo- (今), allo- and paratypes (3 ㅇ ): Kirimezaki, Pref. Wakayama, 15. IV. 1970, K. SAwada.

Specimens examined: 1 o, 1 우, Kirimezaki, (15. IV. 1970, K. SAwADA), 1 우, 
(16. V. 1970, K. SAwada), both in Pref. Wakayama; 1 $\delta, 4$ 우, Aburatsubo (26. VI. 1955, T. AOKI), 2 今, 3 우, Manazuru, (18. III. 1954, S. UENo), 1 우, Koyurugi, (12. V. 1953, T. Aokı), all in Pref. Kanagawa; 1 9 , Izu-Oshima, Pref. Tokyo, (6. V. 1955, T. Aокı); 1 今, Aoshima, Pref. Miyazaki (26. 111. 1971, R. Yosis).

The species is closely allied to $B$. tsutsuii, but easily distinguished from it by distally dislocated $\gamma$ setula of the labial palpus, longer glossa, different form of the aedeagus and shorter copulatory piece. The spermatheca of females is more complicated.

\section{Halorhadinus g. nov.}

Typus: Halorhadinus aequalis sp. $\mathrm{n}$.

The genus is, without doubt, nearly related to Bryothinusa, the above mentioned characters of Myllaenini (p. 81) being applicable to this genus. But, in contrast, the glossa of the new genus is elongate enormously, attaining one half of the labial palpus. In this respect the genus is near Antarctophytosus EnderLeIN, 1909 of the Subantarctic Islands. For their exact identity further studies must be made. Some setae of the labial palpus are apparently falcate or lanceolate in two species described here.

\section{Halorhadinus aequalis sp. $\mathrm{n}$.}

(Text-fig. 5)

Female: Ground colour is brown, partly rufescent, weakly shining and clothed very short inconspicuous pubescence; head and pronotum are uniformly pigmented; abdomen is intensively black, becoming paler posteriorly; antennae are evenly reddish brown; legs are somewhat paler. Head is depressed as a whole, broadly deplanate on the upper surface; an obsolete small depression on the vertex and a punctiform setiferous fovea on each side behind the depression can be discerned; the frontal margin is truncate, but faintly emarginate at the middle; the infraorbital carina is entire and directly jointed with the subgenal margin; just in front of the antennal insertion there is a small foramen, well visible when the antennae are directed back-wards. It may penetrate into the interior toward the oral cavity; the microsculpture is indistinct. Eyes are nearly flat, composed of numerous fine facets together with some 20 distinct setae, much longer than the diameter of each facet and distributed on the posterior half of the eyes. Antenna is slender, not dilated distally; ratio of segments as $I 27 \times$ 12 : II $27 \times 11$ : III $20 \times 9.7$ : IV $16 \times 10: \mathrm{X} 17 \times 14: \mathrm{XI} 28 \times 13.5$. Labrum (fig. B) is rectangular with the arcuate lateral corner; the anterior margin has a broad emargination at the middle, whose bottom is sinuately produced; seta $p-1$ is longer than $p-2 ; m-2$ is much longer than $m-1$ and placed distal to $p-1 ; d-1$ may be the largest and lateral to $m-2$; all three rows are characteristically short; beside them there are numerous secondary setae as usual in the genus, those along the lateral margin are curled inwards and larger than those on the inner side. The $a$-sensilla of the labral 
margin (fig. C) is long, setiform and curved; $b$ is elongate, pointed, but $c$ is broad and obtuse; along the lateral margin 3 spiniform sensillae (fig. B) are present, the apicalmost one is more or less reniform. Mandible (fig. D) is elongate, gently curved to form a short apical hook; there are 8 conspicuous setae and a minute apical sensilla laterally; the right mandible has a preapical and a median tooth along the inner margin in addition to the indistinct flat serration, they are almost reduced in the left mandible. The prostheca ( $t$ in fig. D) is well-developed, reaching the apex of the mandible; the marginal ciliation is very strong at the middle, where each cilium is simple and arranged in double row as seen in fig. E. Maxillary palpus is long and slender; segment $I$ is clearly longer than wide; II is narrowly elongate, weakly dilated distally, longer than III and without any distinct microsculpture; III is a little wider and more richly pigmented than II; IV (fig. $\mathrm{H}$ ) is small, somewhat geniculate and dilated before the middle and has a minute apical sensilla; the basal sensillae are long, filamentous and reaching the middle of the segment. Lacinia (fig. F) is narrowly elongate, subparallel and curved at the apex forming a stout hook; the distal comb occupies fully the anterior half of the lacinia and consisting of up to 10 short spines, widely separated from one another and almost equal in size; apicalmost 3 spines are, however, smaller and more reduced than the apical hook; behind them there is a row of fine, curved spines continuous to the row of straight basal spines. Galea (fig. G) is spiniform, densely fringed with long cilia along the inner margin; some stout cilia on the apex and a long curved basal sensilla of the distal lobe ( $\mathrm{r}$ in fig. $\mathrm{G}$ ) are present. Labial palpus (fig. I) is narrowly elongate, straight; the first articulation is reduced; segment II is short and narrow, apically rounded, distinctly verrucose and with the fine apical vesicle; the setae are aggregated to the outer basal part of the palpus and most of them are characteristically spatulate or falciform; setula $\alpha$ is placed on the basal margin of the palpus; $\beta$ is well defined, situated near the middle between $t p$ and base; $\gamma$ is short, between $f$ and $h$ in position; $\delta$ is posterior to $e ; a$ is absent; $b$ is just behind $f$ and subequal to it in length; $c$ is long, placed on the level with $h$; $d$ is proximal to $c ; g$ is close to the level of $e ; m p$ is as small as $t p$ and apicalmost in position; Glossa (fig. I) is narrow, enormously long, protruded beyond the middle of the basal palpal segment and bears 4 pairs of fine sensillae, the basalmost of which tends to become a minute spinula; the paired basal pores are standing close together. Distal setae of the prementum are curved inside and touching to one another; the median area of the prementum (fig. I) is a little dilated in the middle and devoid of pseudopores; on the lateral area there are 1 setal, 2 real pores together with several pseudopores; the anterior margin is nearly straight in its full length. The paraglossa is produced apically to a narrow process and with very long cilia. Mentum (fig. $\mathrm{J}$ ) is broadly emarginate, with many setae and fine pores; the external corner is triangular, but not so acutely produced as in Bryothinusa; seta $u, v, w$ are all on the apex of the corner. Pronotum is gently convex above, deplanate on the middle and with a median shallow depression extending posteriorly without reaching the extreme base of the pronotum. In addi- 


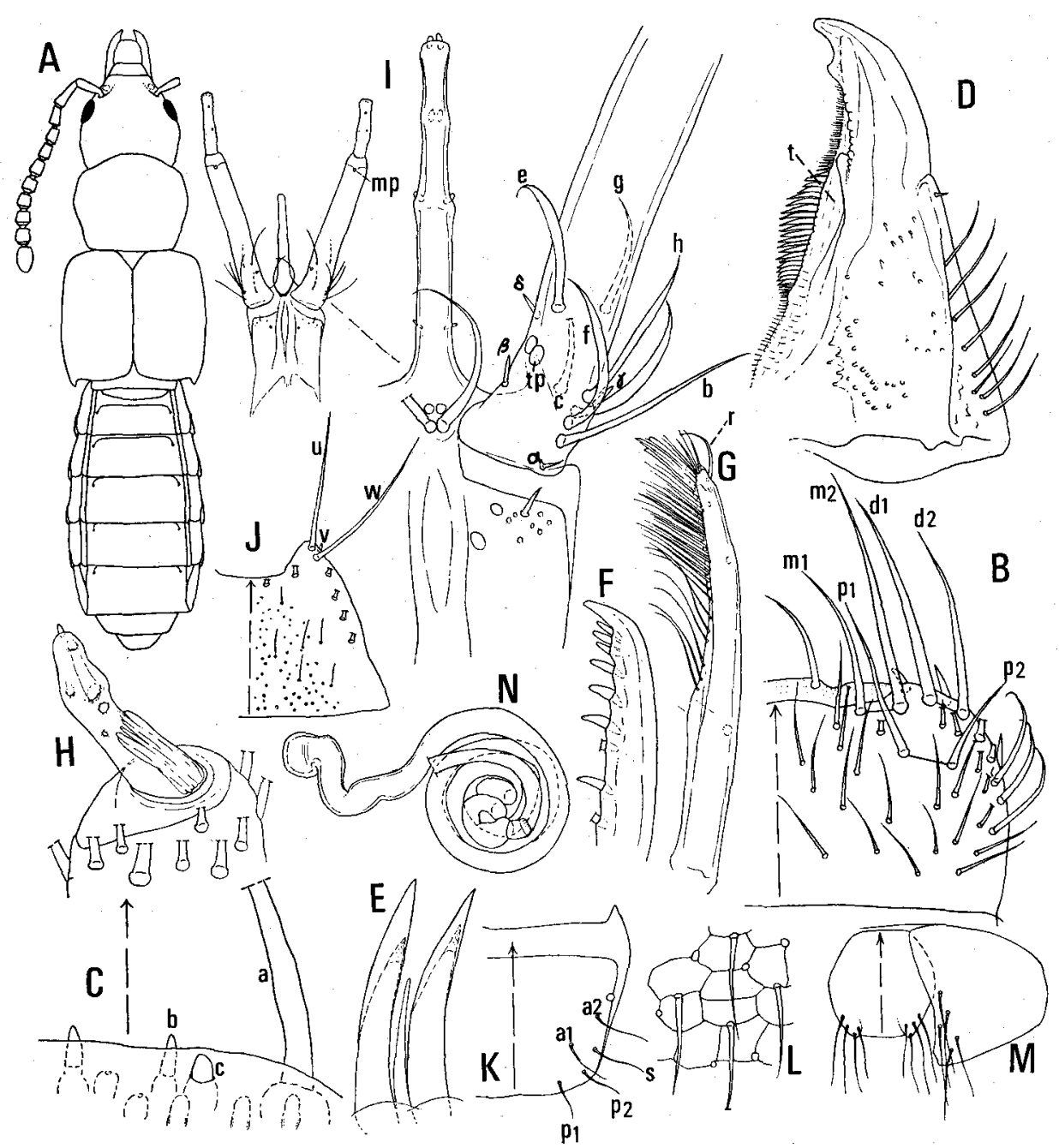

Fig. 5. Halorhadinus aequalis sp. n. A, Habitus; B, Labrum; C, Labral margin; D, Right mandible; E, Cilia of mandibular prostheca; F, G, Lacinia \& Galea; H, Segment IV of maxillary palpus; I, Labium; J, Mentum; K, Terg. VIII; L, Microsculpture of Terg. VIII; M, Terg. IX; N, Spermatheca.

tion, a pair of punctiform, small foveae are present on each side of the disc, which may be seen under a favourable condition; the lateral margin is finely bordered, but only the basal one fourth of it is visible in the dorsal view; dorsum is very finely pubescent and densely sculptured throughout. The pronotual epipleuron is wholly visible from the side. The prosterum is sharply carinate along the middle and with the short acute apex. Elytron is clearly emarginate behind, with dense microsculpture but without any erecting setae. Metathoracic wing is normally developed. The mesosternum is 
shortly pointed behind and finely carinate near the apex of the process. Metasternum is ample, not modified, fincly and evenly punctured. All the tibiae are densely pubescent and with some blunt spines near the apices. Tarsal segments are 4,4,5, and related as 19:17:17:30 in fore-; 20:18:18:34 in mid-; 28;22:20:20:36 in hind-legs. No empodium on any tarsus. Abdomen is more roughly punctured and sculptured than on the elytra; tergite III to VI may be depressed basally. Terg. VIII (fig. K) is broadly truncate on the posteior margin, but faintly emarginate at the middle; among $5+5$ principal setae $a-2$ is proximally dislocated near the stigma so that the anterior row appears to be quite oblique toward the posterior margin; one long additional seta ( $\mathrm{s}$ in fig. $\mathrm{K}$ ) is present near the lateral margin; the surface is covered with dense pubescence, longer toward the extremity and bearing a transverse reticulation mingled with micropores. Sternite VIII is lightly rounded behind, with $7+7$ principal setae. Terg. IX (fig. M) is fairly shorter than the paratergites, broadly truncate posteriorly and with a pair of short, blunt lateral processes, the produced area bears some longer setae.

Spermatheca (fig. N) has a long duct, coiled up many times and terminating shortly twisted and raised; it is distinctly contorted before the reduced bursa, whose umbilicus is quite absent.

Length $3.0 \mathrm{~mm}$ (head long $0.47 \mathrm{~mm} \times$ wide $0.53 \mathrm{~mm}$; pronotum $0.52 \mathrm{~mm} \times$ $0.61 \mathrm{~mm}$; elytra $0.69 \mathrm{~mm} \times 0.77 \mathrm{~mm})$.

Holo-(우) and paratype (1 우): Shingu, Pref, Wakayama, (14. IV. 1970, R. Yosir).

That the right mandible bears a premolar tooth in addition to the usual molar tooth and the prostheca bears simple, acutely pointed cilia is the characteristic feature of the present new species.

The distal comb of the lacinia is equally dentate. Paratergite of the terg. IX is relatively short and spermatheca is densely coiled.

\section{Halorhadinus inaequalis sp. $\mathrm{n}$.}

(Text-fig. 6)

Female: Ground colour is brown, moderately shining and shortly pubescent as in the preceding species. Head is little paler, somewhat rufescent anteriorly; pronotum, elytra and abdomen are uniformly pigmented, but paler to the end; antennae and legs are rufescent, the former lightly paler distally. Head is gently convex and broadly deplanate above, obsoletely depressed on the middle of the epicranium; the integument is rather coarsely sculptured on the middle, with a finely rugose appearance. Eyes are not convex from the contour of the head and composed of numerous fine facets bearing some 12 long setae. The foramen of the antennal fossa, seen in the preceding species, is indistinctly present, but it may be closed by the thin cuticula. Ratio of antennal segments as I $30 \times 11$ : II $28 \times 10$ : III $17 \times 10$ IV $13 \times 11: \times 16 \times 15$ : $\mathrm{XI} 26 \times 15$, Labrum (fig. A) is seemingly narrow, indistinctly emarginate; the chaetal 
arrangement is essentially as in the preceding species; the loci of the principal setae are obscured by numerous secondary setae; $m-1, m-2$ are situated near the anterior margin, while $p-1, p-2$ are on the middle of the labrum; among $3+3$ short spiniform lateral sensillae the basalmost one ( $\mathrm{s}$ in fig. A) is fairly posterior to $p-2$ in position. Sensory elements of the labral margin are almost the same as in the preceding species. Mandible (fig. B) is narrow, elongate and acutely hooked apically; in the right mandible the median tooth of the inner margin is loosely eroded and no premolar tooth is present. The prostheca ( $t$ in fig. B) is attaining beyond the apex of the mandible; the ciliation

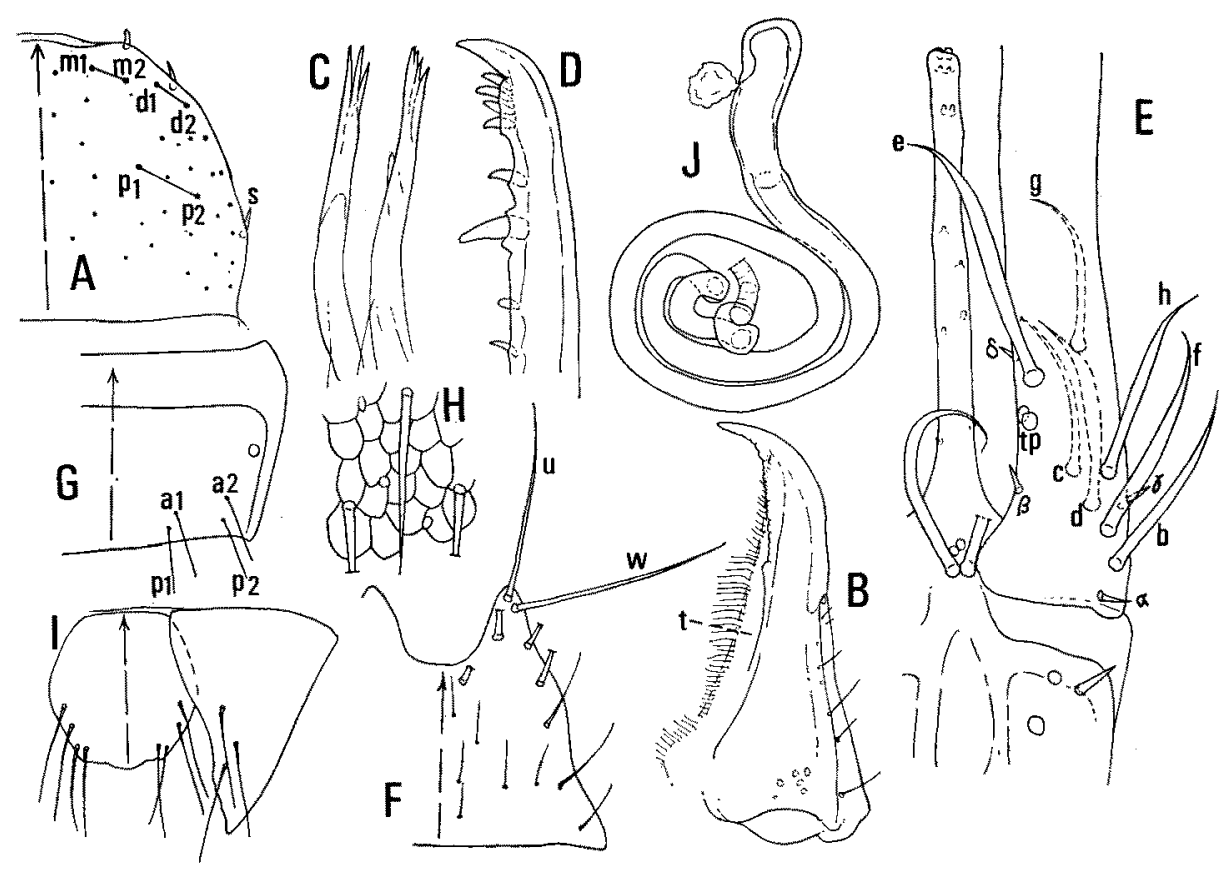

Fig. 6. Halorhadinus inaequalis sp. n. A, Labral chaetotaxy; B, Right mandible; C, Cilia of mandibular prostheca; D, Lacinia, E, Labium; F, Mentum; G, Terg. VIII; H, Microsculpture of terg. VIII; I, Terg. IX; J, Spermatheca.

is weaker and scarcer on the middle than in H. aequalis; each cilium (fig. C) is bi- or trifurcate apically. Maxillary palpus is relatively shorter as compared with the preceding species. Lacinia (fig. D) is narrowly elongate, with a very stout apical hook; the arrangement of spines of the distal comb is peculiar, the subapical ones are 4 in number in contrast to 3 in $H$. aequalis and one spine at about the middle is much larger than others in the present species, whereas they are all subequally large in the preceding species. Galea is filiform, but the basal sensilla of the distal lobe is short and erecting. Labial palpus (fig. E) is straight; in chaetotaxy setula $\delta$ is anterior to $e$ in position; seta $a$ is missing; $d, e, f$ are more or less spatulate; $e$ is large; $g$ is anterior to $e$. Glossa 
(fig. E) is enormously long and terminating in a truncate apex, it bears many small sensillae variable in loci. The distal setae of the premetum are as in the preceding species. Prementum (fig. E) bears no pseudopores, but the lateral area has one setal and two real pores. The external corner of the mentum (fig. E) is strongly produced in a triangular process, so that the anterior margin is deeply notched; seta $u$, $w$ are equally long and located close to the apex; peculiarly the mentum bears no $v$ setula in two specimens examined. Pronotum is distinctly constricted behind; the punctiform foveae on the disc are very poorly represented; the integument is coarsely sculptured especially on the middle area. Elytron is clearly emarginate behind and densely sculptured throughout. Metathoracic wing is present. Tarsal segments are 4,4,5, their relative lengths are as $23: 20: 22: 37$ in fore-; $27: 25: 25: 42$ in mid-; $35: 30: 29: 27: 42$ in hind-legs. No empodium on any tarsus. Abdomen is obsoletely sculptured and partially with some punctures. Tergite VIII (fig. G) is poorly narrowed and broadly truncate behind, with $4+4$ principal setae; they are distally situated; $a-2$ is far remote from the stigma; the medial seta being absent; the microsculpture on the middle area (fig. $\mathrm{H}$ ) is of an imbricate type, each element is elongate and mixed with the micropores. Terg. IX (fig. I) is nearly similar to the preceding, but the pesterior margin is more finely rounded in the middle and the produced corner on each side is completely effaced; the paratergite is acuminated to a narrow pointed process as shown in fig. I.

The spermatheca (fig. J) is more loosely coiled as compared with the preceding species and there is a contortion before the bursa; a faint constriction is present to delimit the elongate bursa, which bears no umbilicus within.

Length $3.0 \mathrm{~mm}$ (head long $0.56 \mathrm{~mm} \times$ wide $0.56 \mathrm{~mm}$; pronotum $0.52 \mathrm{~mm} \times$ $0.62 \mathrm{~mm}$; elytra $0.70 \mathrm{~mm} \times 0.80 \mathrm{~mm})$.

Holotype( $q$ ): Wakasa-Takahama, Pref. Fukui, (20. V. 1969, K. SAwada), under wracks; paratype (1 + ): Shingu, Pref. Wakayama, (14. IV. 1970, R. Yosis).

Externally the present new species is almost the same as the preceding one, but the labrum is narrower, the mandible is without premolar tooth and the distal comb of the lacinia is unequally dentate, having one larger tooth. Setula $\delta$ on the labial palpus is more distal in position, mentum is more deeply emarginate and the medial seta of the terg. VIII is absent. Spermatheca is simpler.

\section{Diaulota CASEY, 1893}

Typus: Diaulota densissima CASEY, 1893

The genus Diaulota includes some 4 species from the Pacific coast of North America. From the Japanese coasts there have been found two forms both of which are different from the previously known species. As the crucial characters of the genus are somewhat incompletely recognized, the details of the typical species, $D$. densissima CAsey, 1893 are redescribed on the material determined by Dr. I. Moore. Very characteristic to the genus the distal setae of the prementum is quite absent. This 
striking character is very rarely found in the Aleocharinae, being observed only in the halophilous genera of Diaulota, Genoplectes and Liparocephalus as well as in one species related to Brachida of Japan. Secondly the basal two segments of the labial palpus are fused together, with a slight sign of articulation and the setae on it are greatly reduced. Sometimes the slight abnormalities of their location and number may be observed. Thirdly and most strikingly the number of tarsal segments is not fixed, but different from species to species. The number of tarsal segments is re garded as the most fundamental and standard character in the taxonomy of Aleocharinae and this is true of almost all forms known to us. But in the present genus it is quite floating; for instance it is $4,4,5$ in $D$. densissima, as typical to the tribe Phytosi, while it is $4,4,4$ in D. aokii sp. n. and 3,3,4 in D. pacifica sp. n., although there exists no fundamental difference in other characters between them.

The variability of the tarsal number like these cases is already noticed by CHAMBERLIN and Ferris 1929 in D. vandykei Moore, 1956. As to the chactotaxy of labial palpus the following characters may be pointed out as peculiar to Diaulota and its allies: seta $h$ is absent and $g$ is minute. Setula $\beta$ is absent, $\delta$ is largely developed and $\gamma$ is variable with respect to their position and form.

Diaulota densissima CASEY, 1893

(Text-fig. 7)

$$
\text { D. densissima, CASEY, } 1893
$$

Female: Ground colour is dark reddish brown and weakly shining; head and pronotum are equally coloured; elytra and the basal portion of the abdomen are more or less infuscate; antennae are darker proximally and legs are similarly pigmented as in the body. Head is oblong, deplanate above the unmodified epicranium and seemingly narrowed behind the eyes; the integument bears short, dense pubescence around the vertex and distinct microsculpture which is mostly round, flat and scattered as in fig. B. Eyes are lightly reduced in size, composed of about 30 coarse facets and some 7 subequal setae much longer than the diameter of each facet, and confined to the posterior half of the eye surface. Antenna is short, moniliform, the last 3 segments are lightly clubbed and larger than others; ratio of segments as I $15 \times 9$ : II $10 \times$ 8.8 : III $8 \times 7.5:$ IV $6 \times 7: \mathrm{X} 9 \times 13: \mathrm{XI} 14.5 \times 12$. Labrum (fig. C) is broadly rounded, neither emarginate nor sinuate, but with many long setae situated anteriorly; $p-1$ is clearly longer than $p-2$ and placed close to $m-1 ; m-2$ is the largest and far surpassing others; $d-1$ is shorter than $d-2$ and anterior to $p-2$; the proximal row is longer than the medial and distal rows, which are subequal to each other in length; 7 long secondary setae are present. The $a$-sensilla of the labral margin (fig. D) is short, setiform; $b$, $c$ are small, obtuse and their location is variable. Mandible (fig. E) is elongate and broadly incurved apically, with a long and some short setae laterally; the right mandi- 


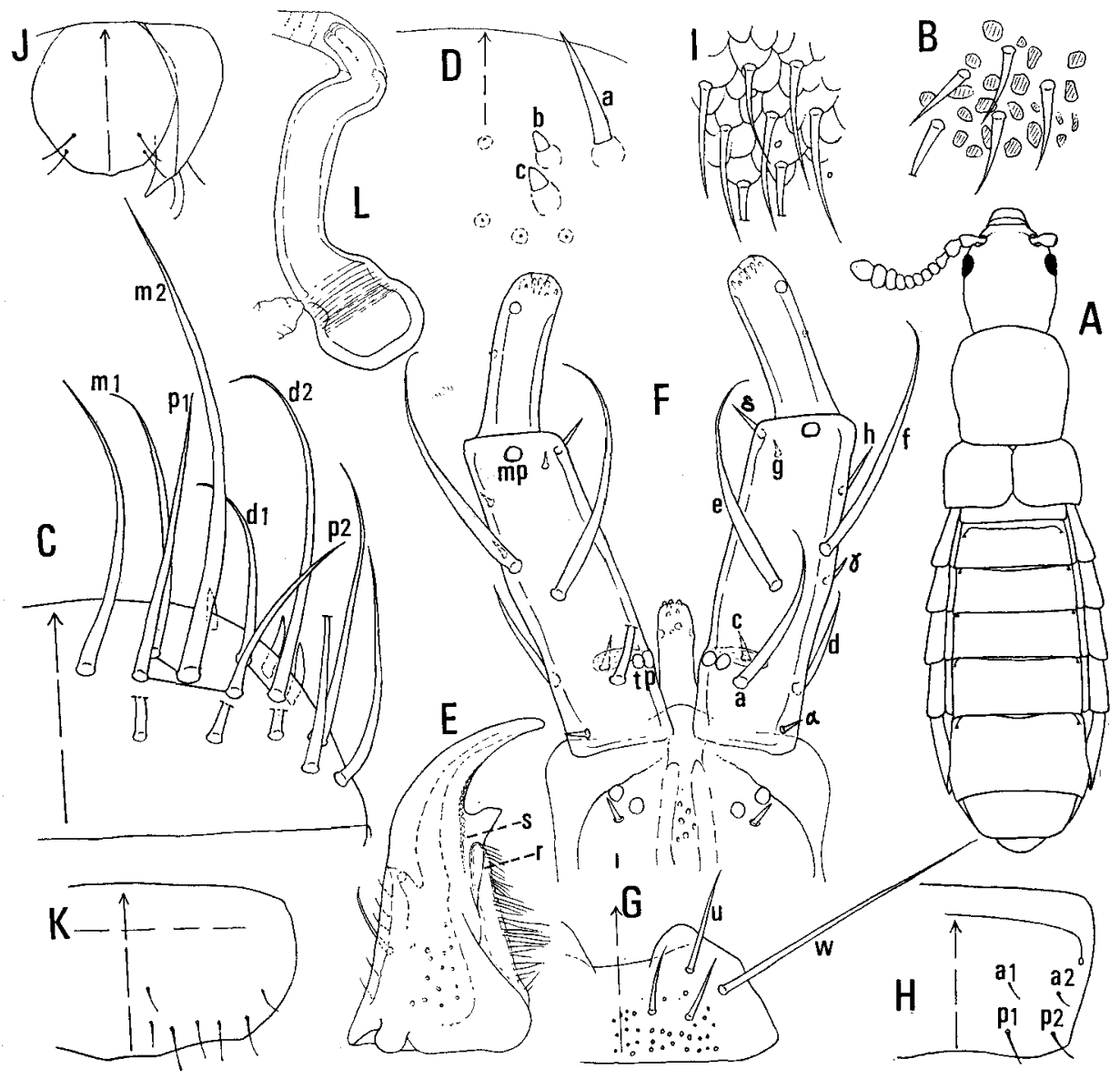

Fig. 7. Diaulota densissima CASEY, from Pacific Grove, California. A, Habitus; B, Microsculpture of head; C, Labrum; D, Labral margin; E, Right mandible \& prostheca (r); F, Labium; G, Mentum; H, Terg. VIII; I, Microsculpture of terg. VIII; J, Terg. IX; K, Stern. VIII; L. Spermatheca.

ble has a robust median tooth on the inner margin; there is a row of fine serrations extending for a distance along the inner margin ( $\mathrm{s}$ in fig. $\mathrm{E}$ ); the left one has no median tooth. Prostheca ( $\mathrm{r}$ in fig. $\mathrm{E}$ ) is well-developed, with long cilia. Maxillary palpus is characteristically short; segment I is longer than wide; II is incrassate distally, fairly incurved along its inner margin and with coarsely imbricate microsculptures; III is longer than II, more dilated and coarsely pubescent; IV is parallel, obtuse, poorly constricted at the middle and with indistinct filamentous sensillae at the base. Lacinia is narrowly elongate, ending in a slender apical hook; there are 9 slender spines forming a long distal comb, the apicalmost spine is much shorter than others, the third one is also short and somewhat separate from others. Galea is normally long, arcuate ante- 
riorly, with some pores behind the middle and near the anterior corner; the distal lobe is short, quite obtuse and densely ciliate, its basal sensillae may be setiform and long, but obscured by long cilia close to them. Labial palpus (fig. F) is robustly sclerotized and seemingly 2 -segmented with an incomplete basal articulation; segment I is much shorter than II; the latter is not narrowed distally; III is parallel, narrower and shorter than II, verrucose on the apex and without an apical spinula; setula $\beta$ and seta $b$ are absent; $\alpha$ is normally short; $\gamma$ is small, usually placed near $f$; $\delta$ is welldeveloped at the anterior end of II; $a, e, f$ are strong and much longer than others; $a$ is postero-lateral to $t p$ in position; $c$ is short; $d$ is long; $e$ is placed inferior to $f$ at the basal one-third of II; $f$ is at about the middle of II; $g$ is characteristically reduced to one minute setula postero-lateral to $\hat{\delta} ; h$ is variable in length and in position, often longer than $g$, but not always in such a state. Distal to $t p$ there is a transparent portion to be regarded as a rest of the articulation of I and II. Glossa (fig. F) is short, entire and not narrowed toward the obtuse apex; it has some minute sensillae but without any setae or basal pores. The median area of the prementum (fig. F) is narrower than the laterals, more or less diverging behind and with a few scattered pseudopores; 2 real pores and 1 setal pore are placed close together. Distal setae of the prementum is quite absent. Mentum (fig. G) is short and produced on the antero-external corner to form obtuse lobes so that the anterior margin is deeply emarginate; secondary setae and numerous pores are present on it; setula $v$ is characteristically absent, while $w$ is very long as compared with $u$ and located posterior to the base of the produced corner. The infra-orbital carina is entire, each constricted anteriorly and reaches directly to the subgenal suture behind the cardo. Pronotum is cylindrically convex and its finely bordered lateral margin is not visible from above; the disc is not modified, but obsoletely depressed before the base; the surface is densely pubescent and sculptured as in the head; the erecting lateral setae are inconspicuous, but the middle one is longer than others. Elytron is lightly arcuate laterally; the posterior margin is not emarginate before the external corner, but faintly sinuate at the middle. The metathoracic wing is absent. Prosternal process is acute and sharply carinate in its full length. Mesosternum is not carinate along the middle and shortly pointed behind. Metasternum is finely carinate along the middle. Tarsal segments as 4, 4, 5, their lengths are as 10:9:8:16 in fore-; 10:9:9.5:18 in mid-; 12:12:11.5:11:18 in hind-legs. No empodium on any tarsus. Pubescence of the abdomen are extremely short, but dense throughout. Tergite VIII (fig. $H$ ) is broadly emarginate along the posterior margin; $4+4$ principal setae are inconspicuous; $a-1, a-2$ are reduced and made obscure by dense pubescence; the microsculpture on the middle area is extremely dense, in an imbricate pattern as seen in fig. I. Terg. IX (fig. J) is rounded in outline, with the subtruncate posterior margin faintly produced at the middle. Sternite VIII (fig. K) is short, dilated and rounded laterally and shortly truncate, and emarginate at the middle of the posterior margin.

Spermatheca (fig. L) is $0.18 \mathrm{~mm}$ long; the duct is short, not narrowed toward the end, but more or less contorted at the extremity; the bursa is ovate, with a minute 
corrugation near the neck and devoid of the umbilicus within.

Length $2.30 \mathrm{~mm}$ (head long $0.44 \mathrm{~mm} \times$ wide $0.36 \mathrm{~mm}$; pronotum $0.44 \mathrm{~mm} \times$ $0.42 \mathrm{~mm}$; elytra $0.30 \mathrm{~mm} \times 0.52 \mathrm{~mm}$ ).

Specimens examined: 2 우, Pacific Grove, Monterey County, California, (24. X. 1954, I. MOORE).

Distribution: Alaska, British Columbia, California.

\section{Diaulota pacifica sp. $\mathrm{n}$.}

(Text-fig. 8)

Male: Light reddish brown in ground colour and weakly shining. Head is a little more rufescent than pronotum and elytra; abdominal segment VI is distinctly infuscate for the most part; antennae and legs are uniformly pigmented, but the latter paler. Head is rounded laterally, evenly convex above and not modified on the epicranium leaving a very small median depression which is discernible in a favourable angle; the frontal margin is lightly rounded; the integument is covered with very short, dense pubescence throughout together with a superficial microsculpture (fig. B). Eyes are considerably reduced, each composed of about 26 facets bearing 7 setulae. Three apical segments of the antennae are not forming a club; ratio of segments as $\mathrm{I} 20 \times 8$ : II $13 \times 8:$ III $10 \times 6.5:$ IV $7 \times 8: X 10 \times 11: \mathrm{XI} 17 \times 1 \mathrm{l}$. Labrum (fig. G) is as in the preceding species, but shorter and more strongly rounded laterally; the setae are arranged in the same manner, but seta $p-2$ is removed distally and close to the middle of the distal row; the secondary setae are 5 in number. The $a$-sensilla (fig. D) of the labral margin is setaceous, but short; $b$ is rather obtuse; $c$ is acute and longer than $b$. Mandible is slender, strongly curved anteriorly and with 3 fine setae laterally; the right mandible has a stout, pointed tooth at the middle of the inner margin. The prostheca is narrow and is fringed with long cilia basally. Maxillary palpus is short and stout; segment $I$ is longer than wide, with a minute setula interiorly and a long seta exteriorly together with 2 apical pores; segment II is incrassate, clearly sinuate along its inner margin and distinctly reticulate all over; III is broad and scattered with fine pubescence; IV is normally short, obtuse, with long filamentous sensillae and without apical spinula. Lacinia has the well-developed distal comb which is composed of 8 loosely arranged, long spines together with up to 3 short spines on the inner side; the distance between the third and fourth spines is large and the first spine is smaller than the second. Galea is nearly parallel, gently curved along its outer margin and bearing several sensory pores on it; the distal lobe is considerably reduced, with an obtuse apex and fringed with long cilia. Labial palpus (fig. E) is as in the preceding species, the articulation between the segment I and II is incomplete; setula $\beta$ and seta $b, h$ are quite absent in this species; $\alpha$ is close to the lateral margin; $\gamma$ is small, usually posterior to $f$ and may be doubled, while $\delta$ is well-developed and lateral to the minute 


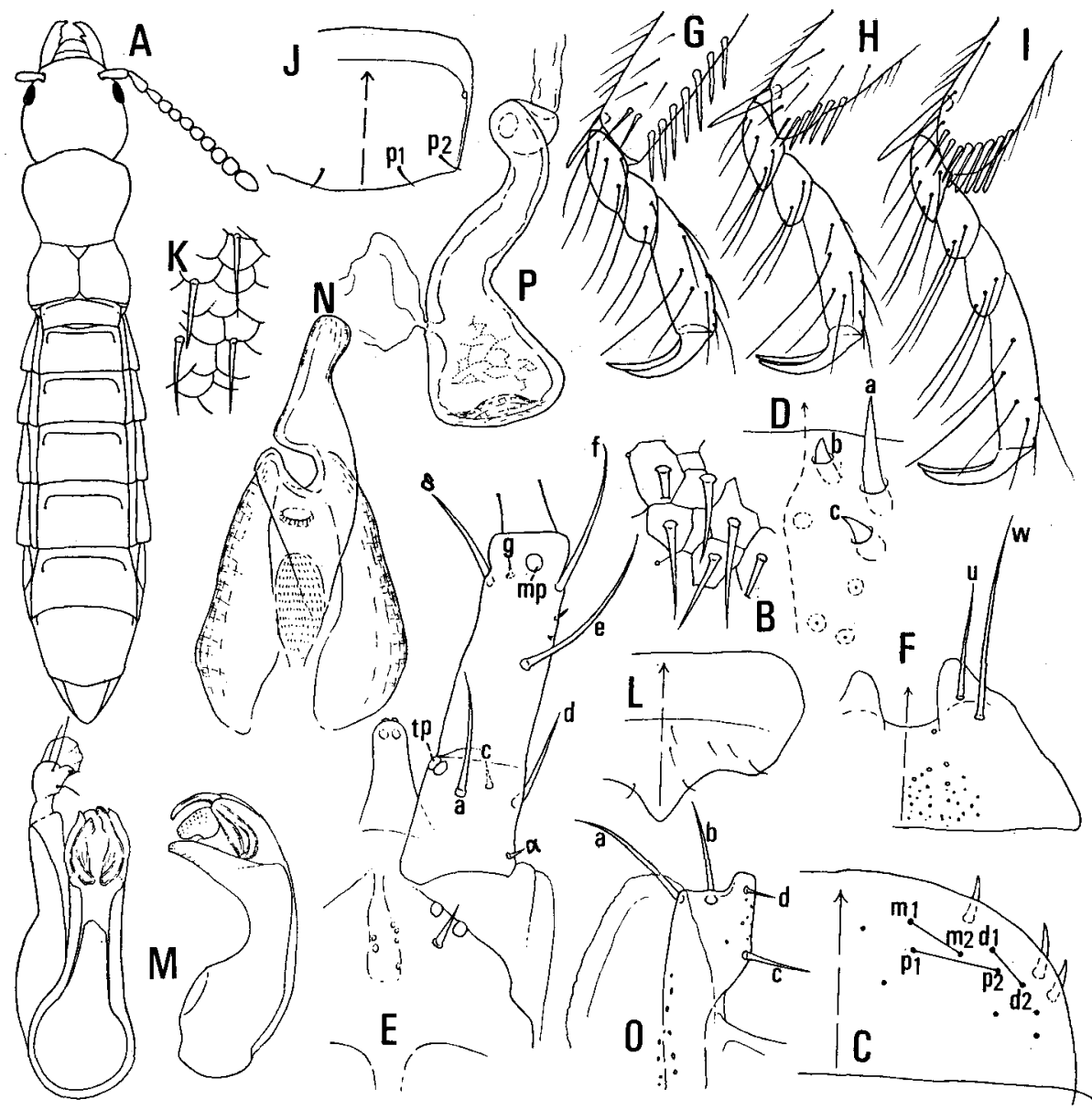

Fig. 8. Diaulota pacifica sp. n. A, Habitus; B, Microsculpture of head; C, Labral chaetotaxy; D, Labral margin; E, Labium; F, Mentum; G, H, I, Fore-, mid- \& hind-tarsus; J, Terg. VIII; K, Microsculpture of terg. VIII ; L, Stern. VIII; M, Aedeagus (dors. \& lat. view); $\mathrm{N}$, Copulatory piece; $\mathrm{O}$, Distal sclerite of left paramere, $\mathrm{P}$, Spermatheca.

$g$ in position; $c$ is very short as compared with $d$, the latter is normally long and on the lateral margin; $e$ is removed proximally to the middle area of the segment. Glossa (fig. E) is nude, rounded apically, dilated basally and with some minute sensory elements on the apex; the basal paired pores are quite absent. Prementum (fig. E) is triangularly acuminate, the distal part is obliterate; the median area is normally wide and with a few pseudopores; 1 setal and 2 real pores are well defined and the latter is on the margin, but devoid of the pseudopores on the lateral area. Mentum (fig. F) has the antero-external corner abruptly produced to form a thin, lobate process, on which the setae $u, w$, are standing rather close together. Pronotum is convex above, deplanate along the almost unmodified disc; 3 erecting lateral setae are long, but fine; 
the surface is covered with fine dense pubescence alike the head, leaving a median area very narrowly impunctate. Elytron is gently convex above, more roughly punctured than on the pronotum and not emarginate postero-externally; the suture is confluent in full length. The metathoracic wing is absent. Abdomen is finely, but densely pubescent throughout. Tergite VIII (fig. J) is simply rounded behind, but an obsolete sinuation just before the lateral corner is discernible; $a-1, a-2$ are not differentiated, while $p-1, p-2$ are clearly observed; the microsculpture on the middle area (fig. $\mathrm{K}$ ) is imbricate, but partially obsolescent. Terg. IX is more rounded behind than in the preceding species. Sternite VIII (fig. L) is sharply cuspidate behind, deeply emarginate laterally and with indistinct principal setae. Tarsal segments are 3,3,4; they are related as 17:17:33 in fore-; 18:18:37 in mid-; 19:22:22.5:42 in hind-legs. No empodium on any tarsus.

Aedeagus (fig. M) is $0.38 \mathrm{~mm}$ long. In the dorsal view the median lobe is narrowly elongate, almost parallel in the anterior half; in the lateral view the median lobe is deeply constricted distally and protruded to form a distinct apical lobe, which is laterally compressed to a beak, where an apical process of the copulatory piece and a membraneous lobe of the suspensoria are exposed. The copulatory piece (fig. N) is $0.12 \mathrm{~mm}$ long; the apical process is a large prolongation nearly fusiform and bearing a large incision on the left side; the basal part is decurved anteriorly, mostly evanescent basally; there is an oblong, thin median piece of the copulatory piece. The suspensoria are small, rounded and situated beneath the corpus. The distal sclerite of the paramere (fig. $\mathrm{O}$ ) is short, subquadrangular with a briefly produced corner; seta $a$ and $b$ are placed on the outer corner and equally long, while $c, d$ are remote from each other.

Length $3.10 \mathrm{~mm}$ (head long $0.40 \mathrm{~mm} \times$ wide $0.41 \mathrm{~mm}$; pronotum $0.38 \mathrm{~mm} \times$ $0.41 \mathrm{~mm}$; elytra $0.25 \mathrm{~mm} \times 0.39 \mathrm{~mm}$ ).

Female: Terg. VIII is simply rounder at the posterior margin as in the male, but an obsolete sinuation before the corner is almost disappeared. Stern. VIII is as in males, but less remarkably. The spermatheca (fig. P) is small, $0.10 \mathrm{~mm}$ long; the duct is briefly contorted at the end and dilated toward the robust bursa, which bears a large outburst near the neck. Slight reticulation covers the most of the surface and there is a weakly convex umbilicus within.

Holo - (令), allo- (ㅇ) and paratype (1 우): Kirimezaki, Pref. Wakayama, (15. IV. 1970, R. Yosi and K. SAwada).

Other specimens examined: $1\{$, 2 우, Cape Manazuru, Pref. Kanagawa, (22. II. 1951, T. Aoki), 1 ㅇ, Ibid. (18. III. 1954, S. UeNo).

The species is unique in its slender body and light colouration. The lst segment of the labial palpus is apparently longer than wide. Glossa is basally dilated and the microsculpture on the head and tergite is quite different from that in other species. The numbers of tarsal segments are reduced to $3,3,4$ without exception in all examples examined as already mentioned. 


\section{Diaulota aokii sp. $\mathrm{n}$.}

(Text-fig. 9)

Female: Ground colour is black and made subopaque by dense microsculpture. Trophi, pronotum, elytra and legs are somewhat rufescent; antennae are paler proximally. Head is ovate, not transverse, widest at the post-genae, evenly convex above and broadly deplanate or faintly depressed on the middle; surface is densely covered with a microsculpture composed of many, small setiferous umbilicus (fig. B) to give a rugose appearance. Eyes are moderate in size, but shorter than the post-genae and composed of more than 30 facets, with only one seta near the posterior end. Antenna is short, the last 3 segments seemingly larger than others; ratio of segments as $\mathrm{I} 19 \times$ $10:$ II $15 \times 9.5:$ III $10 \times 8:$ IV $8 \times 8.5: \mathrm{X} 11 \times 12: \mathrm{XI} 17 \times 12$. Labrum (fig. C) is transverse, broadly trancate in front, evenly rounded on each side and bearing 3 acute sensillae marginally, whose intermediate sensilla ( $\mathrm{s}$ in fig. $\mathrm{C}$ ) is much larger than others; seta $p-1$ is fairly longer than $p-2 ; m-2$ is much larger than others; $m-1$ is seemingly smaller than the secondary seta close to it; $d-2$ is fairly longer than $d-1$; the distal row is nearly equal to the medial row in length; there are some 7 long secondary setae. The $a$-sensilla of the labral margin is setiform and normally long; $b$ is short, but merely pointed; $c$ is stouter than $a$ and thick at the base. Mandible is alike that of $D$. pacifica, but stouter and bears very short setulae laterally; the right one has a blunt median tooth on the inner margin. Prostheca is densely fringed with cilia which are longer basally. Maxillary palpus is short; segment $I$ is longer than wide; II is strongly incrassate, seemingly thicker than III, with coarse setae marginally and with well defined microsculpture; III is clearly longer than II; IV is stout, neither constricted at the middle nor dilated apically; the apical spinula is converted into a blunt, short protuberance. Lacinia is narrow; the distal comb is composed of some 7 short, blunt spines not compactly arranged; among these spines the apicalmost one is much smaller than others. Galea bears some coarse pores basally; the distal lobe is short, obtuse, densely ciliated and with the basal sensilla represented by a long seta. Labial palpus (fig. E) is, as a whole, stouter than in D. pacifica ; segment $\mathrm{I}$ is apparently broader than long; setula $\beta$ is absent and $\gamma$ is variable in loci and number, usually placed behind $f ; \delta$ is long and lateral to the strongly reduced $g ; a$ is remote from $t p ; e, f$ are very large and much longer than $a$, the former is located at the middle area of the segment as in the preceding species. Glossa (fig. E) is long, mostly parallel, clearly extending beyond the level of $t p$ and with minute processes on the apex. Prementum (fig. E) is poorly sclerotized; the distal setae are absent; the median area is narrow, more or less dilated behind and with a few coarse pseudopores; the real pores and setal pore of the lateral area are situated at the same level. Mentum (fig. F) has the antero-external corners each strongly produced to a broad, lobate process as in the preceding species, but the processes are less separated from each other; setula $v$ is missing; $u$ is placed at about 
the middle of the produced area and is much shorter than $w$, which is remote from $u$. Pronotum is more or less cylindrical, posteriorly deplanate at the middle and obsoletely depressed along the basal margin; it is widest before the middle and then abruptly narrowed toward each end to give an angulate appearance; 3 lateral erecting setae are short; the surface is distinctly sculptured as in the head. Elytron is faintly sinuate postero-externally and with the microsculpture a little rougher than on the pronotum. Metathoracic wing is completely reduced. Tarsal segments are $4,4,4$, related as

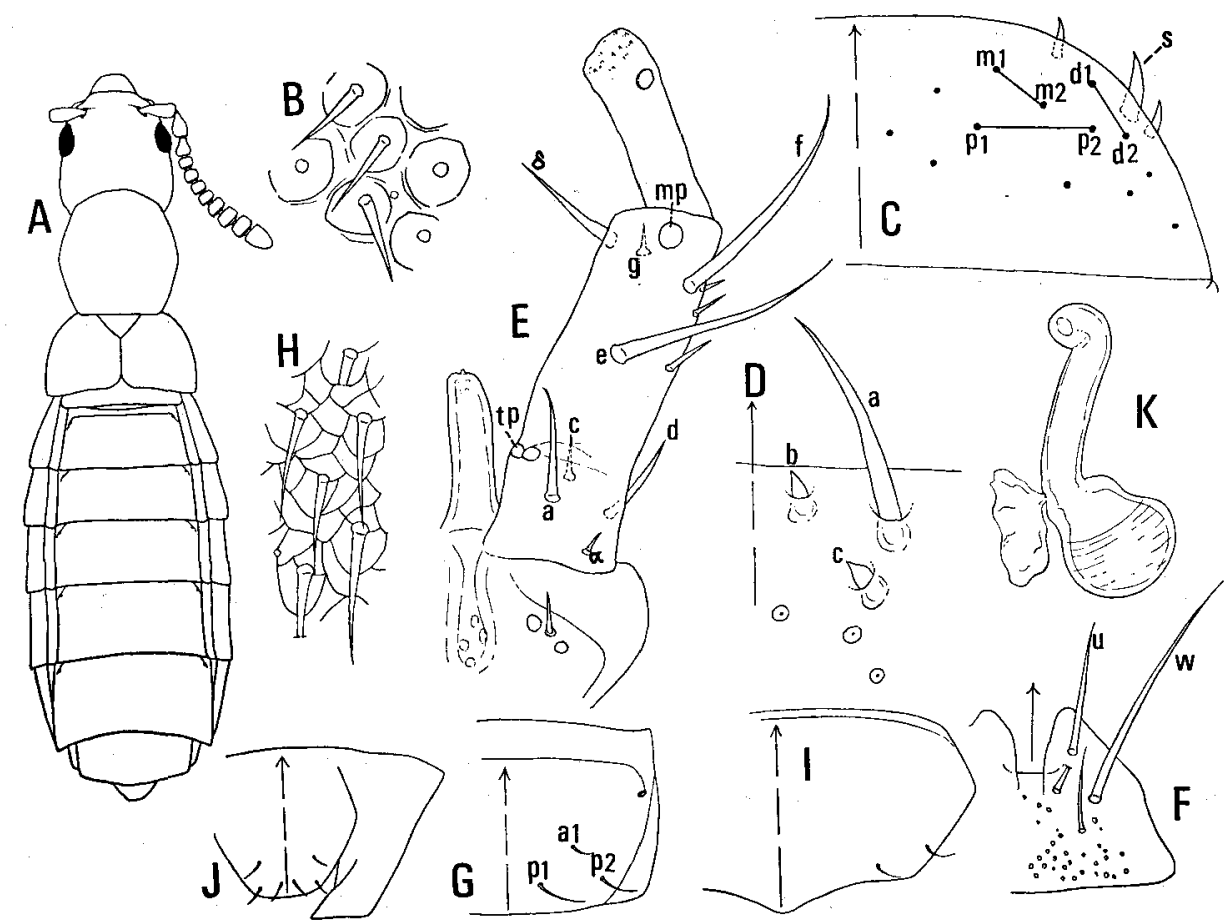

Fig. 9. Diaulota aokii sp. n. A, Habitus; B, Microsculpture of head; C, Labral chaetotaxy; D, Labral margin; E, Labium; F, Mentum; G, Terg. VIII; H, Microsculpture of terg. VIII; I, Stern. VIII; J, Terg. IX; K, Spermatheca.

$20: 21: 21: 33$ in fore-; $21: 20: 22: 40$ in mid-; 25:25:26:60 in hind-legs. No empodium on any tarsus. Tergite VIII (fig. G) is truncate or faintly rounded on the posterior margin; seta $p-1$ is longer than $p-2 ; a-1$ is the shortest, $a-2$ is not differentiated; the microsculpture on the middle area is represented by an irregularly imbricate, dense reticulation as seen in fig. $\mathrm{H}$. Terg. IX (fig. J) is nearly truncate behind. Sternite VIII is weakly sinuate and produced behind, with reduced principal setae.

Spermatheca (fig. $\mathbf{K}$ ) is $0.13 \mathrm{~mm}$ long, alike that of $D$. pacifica, but in the present new species there is a nuchal constriction delimiting the bursa; the duct is deflexed at the apex; the bursa is ovate basally, sinuate behind the neck and without the umbilicus. 
Length $2.60 \mathrm{~mm}$ (head long $0.50 \mathrm{~mm} \times$ wide $0.38 \mathrm{~mm}$; pronotum $0.46 \mathrm{~mm} \times 0.43$ $\mathrm{mm}$; elytra $0.32 \mathrm{~mm} \times 0.55 \mathrm{~mm})$.

Holotype (우): Shore of Motomura in Izu-Oshima, Pref. Tokyo, (8. III. 1951, T. AоKI).

The species resembles $D$. densissima CASEY, 1893 in body colour, but the head is broader, pronotum is more angulate and integumentary sculpture is quite different. In the labial palpus $g$ is more apically located and $\delta$ is clearly shorter. The tarsal segments are $4,4,4$ in number.

The species is dedicated to Mr. Tadao Aoki in Tokyo, who has kindly furnished me with the rich material of the intertidal Aleocharinae including this new species.

\section{Genoplectes K. SAWADA, 1955}

Typus: Genoplectes uenoi K. SAwadA, 1955

The genus is closely related to Diaulota CASEY, 1893, but different from it in the following points: glossa is small and blunt as in Diaulota, but it is beset with a pair of small setae. Labial palpus is clearly divided into three segments and seta $c, d$ are quite absent. Mentum is emarginate in front as in Diaulota, but much shallower. Tarsal segments are 4,4,4 as in the typical species, but it may be rather a specific character and not to be regarded as a generic nature. Previously the genus is placed in Hygronomini by the number of tarsal segments, but now it must be regarded as a kind of Phytosi by the resemblance in labial structure and cther features.

\section{Genoplectes uenoi K. Sawada, 1955}

(Text-fig. 10)

Male: Reddish brown in ground colour and weakly shining. Head is indistinctly darker than pronotum and elytra; abdomen has the distal segments much more infuscate than the proximal part; both antennae and legs are uniformly pigmented. Head is oblong, gently convex above and broadly deplanate toward the frons, whose margin is entire and truncate; epicranium is not modified excepting a faint depression on the middle; the integument bears very fine, short pubescence together with superficial microsculpture. The infra-orbital carina is bifurcated basally, but entire. Eyes are strongly reduced, consisting of about 20 facets together with a few long pubescence. Antennae has a moniliform flagellum and 3 thick apical segments; ratio of segments as I $19 \times 8.5:$ II $12 \times 8:$ III $10 \times 7:$ IV $7 \times 7.5:$ X $10 \times 12:$ XI $18 \times 11$. Labrum (fig. B) is nearly semicircular in outline; the principal setae are aggregated on the anterior part of the labrum together with 8 long secondary setae; $p-1$ is longer than $p-2 ; m-2$ is the longest, while $m-1$ is much shorter than the secondary setae which are placed close to it ; $d-1$ is longer than $d-2$ and distal to $p-2$ in position. Three sensillae are situated on 
the lateral margin and subequally short. The $a$-sensilla of the labral margin is setiform, but short; $b$ is pointed; $c$ is quite obtuse, reduced. Mandible (fig. D) is elongate and narrowed to the gently hooked apex; the right one has a tooth in front of the middle of the inner margin; the prostheca is narrow and densely fringed with coarse cilia. Maxillary palpus is robust and 4-segmented; segment $I$ is longer than wide, with a short and a long seta; II is short, incrassate at the middle and with the coarse microsculpture distributed up to the apical part; III is more slender than II; IV is short, scarcely narrowed toward the rounded apex, which is devoid of apical spinula; the filamentous sensillae are narrow and fully reaching to the middle of the last seyment. Lacinia is elongate, with a stout apical hook; the distal comb (fig. F) is welldeveloped and consisting of 8 slender spines interrupted between the third and fourth spines: behind the distal comb the lacinia is densely fringed by fine, long spinulae. Galea (fig. G) is broad, lightly curved apically and with a few, scattered sensory pores; the distal lobe is short, quite obtuse and densely fringed with setae, which are longer along its inner margin. Labial palpus (fig. E) is 3-segmented; seta $b, c, d$ and setula $\beta$ are characteristically absent in this species; $\alpha$ is small, normal in position; $\gamma$ is short, usually situated on the level with seta $e ; \delta$ is normally reduced, apically placed and lateral to $g ; a$ is posterior to the small $t p ; e$ may be subequal to $f$ in length and placed far from the margin; $f$ is distal in position, close to $h ; g$ is apical and shorter than $h ; m p$ is apically placed. Some individual aberrations in the chaetotaxy may often be found; in the type the right palpus bears an additional seta ( $\mathrm{x}$ in fig. $\mathrm{E}$ ) anterior to $h$, while the left palpus bears $\mathrm{x}$ posterior to $\gamma$. Glossa (fig. E) is narrowly elongate, entire and blunt on the apex; it has a pair of small, diverging setae; paired basal pores are missing together with the distal setae of the prementum. The median area of the prementum is narrow and without pseudopores; 2 real pores on the lateral area are located near the anterior margin. A setal pore and some pseudopores are posterior in position. Mentum (fig. $\mathrm{H}$ ) is short, deeply emarginate in front and with many micropores; setula $v$ is absent; seta $w$ is proximally placed and remote from $u$; there are only $1+1$ secondary setae on the middle. Pronotum is cylindrical, not modified above and distinctly constricted basally, with a faint sinuation before theb asal corner; the lateral erecting setae are 3 in number, inconspicuous; the integument has short, but rather dense pubescence all over. The lateral epipleura are entirely visible from the side. The prosternum is shortly pointed behind and with an indistinct imedian carina posteriorly. Elytron is gently convex above, seemingly not emarginate postero-externally and with long, dense pubescence. The metathoracic wing is completely reduced. Tarsal segments are as 4, 4, 4 and related as 15:16:17:28 in fore-; 17:17:17:30 in mid-; $17: 20: 23: 40$ in hind-legs. No empodium on any tarsus. Abdomen is similarly pubescent, but it is more distinct posteriorly. Targite VIII (fig. J) is almost truncate behind, but faintly sinuate at the middle and before the lateral corner; of $4+4$ principal setae $p-1, p-2$ are subequally short, $a-2$ is remote from the stigma; the microsculpture on the middle area is largely obsolescent and of an imbricate-reticular type. Terg. IX 


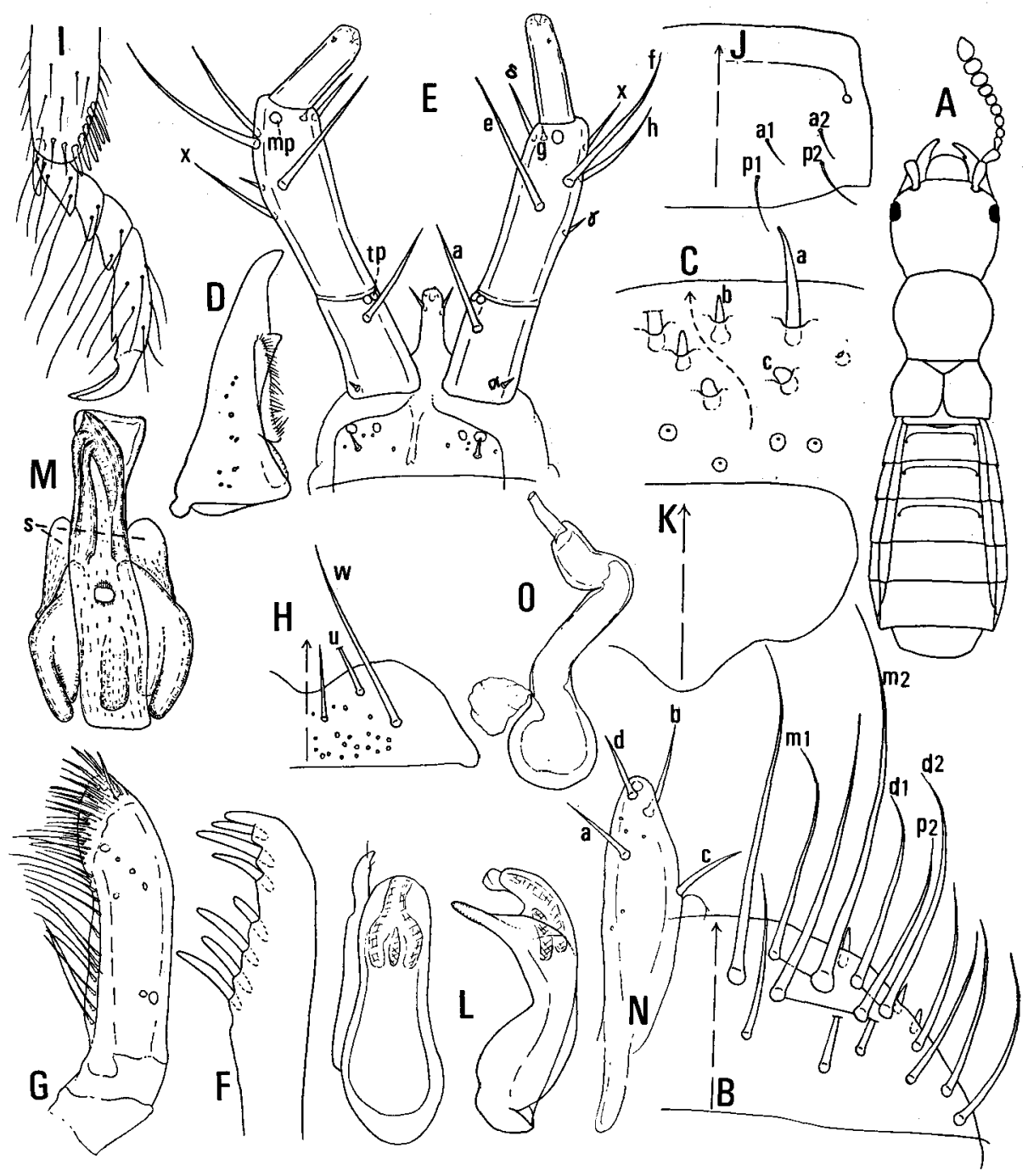

Fig. 10. Genoplectes uenoi K. Sawada, from the Tokara Is. A, Habitus; B, Labrum; C, Labral margin; D, Right mandible; E, Labium; F, G, Lacinia \& glaea; H, Mentum; I, Fore tarsus ; J, Terg. VIII; K, Stern. VIII, L, Aedeagus (dors. \& lat. view) ; M, Copulatory piece; $\mathrm{N}$, Distal sclerite of left paramere; $\mathrm{O}$, Spermatheca.

is broad and merely rounded behind. Sternite VIII (fig. K) is broadly produced on the middle of the posterior margin; the principal setae are not differentiated.

Aedeagus (fig. L) is robust, $0.40 \mathrm{~mm}$ long. In dorsal view the median lobe is oblong, broadly rounded on the apex and lightly constricted at the middle; in lateral view the apical lobe is narrowly prolonged, pointed and bent. Copulatory piece (fig. M) is strongly modified; the apical process is transformed into the quadrangular, 
thin plate, with some thick sclerites on its anterior half, with a small annellus at about the middle; there is a small median sclerite interior to the plate behind the annellus; the suspensoria ( $\mathrm{s}$ in fig. $\mathrm{M}$ ) are a pair of small, rounded sclerites lateral to the copulatory piece. The paramere (fig. L) is small for the median lobe and raised anteriorly; the distal sclerite (fig. $\mathrm{N}$ ) is nearly fusiform; seta $a$ is located at the anterior two-thids, while $b$ is near the apex and slightly longer than $a ; c$ is also longer than $a$ and more proximally placed so that $d$ is far remote from $c$.

Length $2.0 \mathrm{~mm}$ (head long $0.44 \mathrm{~mm} \times$ wide $0.42 \mathrm{~mm}$; pronotum $0.36 \mathrm{~mm} \times 0.39$ $\mathrm{mm}$; elytra $0.25 \mathrm{~mm} \times 0.40 \mathrm{~mm})$.

Female: Head is a little smaller than in the male and basal segments of antennae are shorter. Tergite VIII, IX are alike those of the male, while sternite VIII is not strongly, but lightly produced behind. Spermatheca (fig. O) is simplified and very small for the body; the duct is thick, bent and not coiled; the bursa is ovate and has the outburst near the neck; there is no distinct umbilicus within.

Specimens examined: $1 \hat{\delta}$ (Holotype), Yoriki in Nakanoshima, the Tokara Is. Pref. Kagoshima, (4. VI. 1953, S. Ueno); 1 \&, 3 ㅇ, Kametsu in Tokunoshima, Pref. Kagoshima, (25. IV. 1954, anonymus); $1 \hat{\delta}, 4$ 우, Hatakejima in Seto, Pref. Wakayama, (3. X. 1970, K. Sawada).

The present description of the female is based on one material from Kametsu in Tokunoshima, Pref. Kagoshima. Kametsu specimens agree well with the type. The examples from Hatakejima in Seto are very large, being $2.5 \mathrm{~mm}$ in body length. At first sight they seemed to represent a different species, but in the details of the body and the structure of the genital organ in both sexes it was proved that they agreed well with the type.

\section{Resumé}

Halobious species of Aleocharinae of Japan have been investigated from the new standpoint of view. Nine species of Aleocharinae including one new genus Halorhadinus and five new species are detected. As far as the Japanese forms are concerned, the halobious Aleocharinae falls in two main groups, the one is composed of Bryothinusa, Halorhadinus, which must be included in Myllaenini, while the other group is composed of Diaulota, Genoplectes and Liparocephalus. The latter must be placed into Phytosi for the absence of distal setae of the prementum, etc. During the course of the study it has been revealed that the number of tarsal segments, which has been regarded as one of the most significant characters in the taxonomy of Aleocharinae, varies really from species to species from Japan within the genus Diaulota. 


\section{REFERENGES}

Adachi, T., 1957. The Staphylinid Fauna of Japan. Jour. Toyo Univ., 11: 1-35.

Blackwelder, R. E., 1952. The Generic Names of the Beetles Fam. Staphylinidae. U. S. Nat. Mus. Bull., 200: 483 pp.

CASEy, T. L., 1893. Coleopterological notices, V. Ann. New York Acad. Sci., 7: 281-606.

- 1904. On some new Coleoptera, including five new genera. Canad. Ent., 36: 312-324.

Chamberlin, J. S., and Ferris, G. F., 1929. On Liparocephalus and allied genera. Pan-Pacific Ent., 5:137-143, 153-162.

Enderlein, G., 1909. Die Insekten des Antarktischen Gebietes. Deut. Südpolar Exp. 10, Zool. II: 361-518.

Fenyes, A., 1918-1921. Genera Insectorum. Subfam. Aleocharinae: $453 \mathrm{pp}$.

Ganglbauer, L., 1895. Die Käfer von Mitteleuropa II : 880 pp.

Moore, I., 1956. A revision of the Pacific coast Phytosi with a review of the foreign genera. Trans. San Diego Soc. Nat. Hist., 12 (7): 103-152.

Sawada, K., 1955. Marine Insects of the Tokara Islands VII. Fam. Staphylinidae. Publ. Seto Mar. Biol. Lab., 5(1): 81-87.

1971. Aleocharinae (Staphylinidae, Coleoptera) from the campus of the Seto Marine Biological Laboratory. Publ. Seto Mar. Biol. Lab., 18 (5): 291-315.

Scheerpeltz, O., 1934. Coleopterorum catalogus 130, Staphylinidae: 1501-1831. 